\title{
IMPACT OF CRUDE ALOE VERA GEL ON SILVER NANOPARTICLE-INDUCED LUNG CYTOTOXICITY IN ADULT MALE ALBINO RATS: FUNCTIONAL, HISTOLOGICAL AND IMMUNOHISTOCHEMICAL STUDY
}

By

\author{
Mona Mohamed Abd El-Galil ${ }^{\text {a* }}$ and Ahmad Mohammad Farag Alkot ${ }^{\text {b }}$ \\ a*Histology and Cell Biology Department, Faculty of Medicine (Girls), Al-Azhar \\ University, Cairo, Egypt \\ ${ }^{b}$ Medical Physiology Department, Faculty of Medicine (Boys), Al-Azhar University, \\ Cairo, Egypt \\ *Corresponding author: Mona Mohamed Abd El-Galil
}

Mobile: (+02) 01090305671, E-mail: medicalmona2009@yahoo.com

Institutional e-mail address: mona.elsayed@ azhar.edu.eg

\begin{abstract}
Background: Silver nanoparticles (Ag-NPs) have a wide range of applications due to their broad antimicrobial characteristics. However, Ag-NPs have some extent of oxidative damage to tissues and cell lines which consequently presents the possibility of toxicity. Aloe vera (AV) has been evaluated in treating these toxicological effects owing to its antioxidant, anti-inflammatory, and anti-fibrotic properties.

Objective: Evaluation of the ameliorative effect of Aloe vera gel extract on the serum levels of some oxidative stress markers and inflammatory cytokines and on the histological changes induced by silver nanoparticles (Ag-NPs) in the lung tissue of adult male albino rats.

Material and methods: Thirty-six adult male albino rats were divided into five main groups: Group I kept as the control group, Group II (AgNPs- injected group) injected intraperitoneally by Ag-NPs solution (100 $\mathrm{mg} / \mathrm{kg}$ ) once daily for 4 successive weeks, Group III (combined Aloe vera and Ag-NPs group) received aloe vera gel $(0.4 \mathrm{ml} / 100 \mathrm{gm} /$ day) orally by gastric tube one hour before Ag-NPs administration in the same dose and duration as group II, Group IV (recovery group) received Ag-NPs solution in the same dose and duration as group II and then left for another 4 weeks without treatment and Group V (Aloe vera-treated group) treated with alo vera gel extract in the same dose and duration as group III for 4 consecutive weeks after Ag-NPs administration. At the end of the experiment, final body weight was measured and each of the total antioxidant capacity (TAC), malondialdehyde (MDA), necrosis factor alpha (TNF- $\alpha$ ) and interleukin 6 (IL-6) was measured in serum. Specimens of lungs were processed for histological and immunohistochemical studies. Histomorphometric and statistical analyses were done.

Results: Physically, AgNPs caused reduction in the body weight. Ag-NPs caused disturbance in the antioxidants and elevation in the serum levels of MDA and inflammatory cytokines. These changes markedly correlated with the histological changes in the lung tissues including thickening of interalveolar septa in association with the collapse of lung alveoli, diffuse inflammatory cells infiltration, dilation and congestion of the pulmonary blood vessels, extravasations of red blood cells and pulmonary fibrosis in concomitant with a significant increase in area percentage of collagen fibers within the lung interstitium and around the congested blood vessels. Detached epithelial cells with deeply stained nuclei appeared in the lumen of the bronchioles. Increased mucus secreting goblet cells within the lung bronchioles, positive inducible nitric
\end{abstract}




\section{Mona Mohamed Abd El-Galil and Ahmad Mohammad Farag Alkot}

oxide synthase (iNOS) immunoreactivity within the cells lining alveoli and positive alveolar macrophages CD-68 immunoreactivity were also detected. The protective and curative potential of Aloe vera extract revealed improvement in the antioxidant assays as well as in the histological and immunohistochemical changes, with the protective effect was more pronounced than the curative one.

Conclusion: Aloe vera showed preliminary success in improving the antioxidant capacity and in decreasing inflammatory the cytokine levels. Also, it succeeded in ameliorating the lung cytotoxicity induced by AgNPs owing to its antioxidant and anti-inflammatory potentials.

Keywords: Silver nanoparticles; Aloe vera; Lung; antioxidant.

\section{INTRODUCTION}

Nanotechnology is the characterization, fabrication, and/or manipulation of structures, devices, or materials between 1 and $100 \mathrm{~nm}$. Larger surface area to mass ratio of nanomaterials makes it different from bulk systems and as a result, they become chemically more reactive and can show different optical, magnetic and electrical properties. In recent times, functional nanomaterials have gained much attention in some fields such as environmental treatments (soil, air and water) and medicine (Baun et al., 2017).

Silver nanoparticles (AgNPs) are well known for their antimicrobial properties. Recently, AgNPs have been incorporated into consumer products, personal hygiene products, wound dressings, cosmetics, baby bottles, food containers, nano silver toothpaste and colloidal silver suspensions, designed as nutritional supplements primarily due to these antibacterial and antifungal properties. Also, these nanomaterials have shown potential use in environmental applications such as in bioremediation processes and wastewater treatment (Bridle, 2021).

Occupational exposure to AgNPs occurs in industries such as manufacturing and using nanomaterials, silver smelting, silver refining, and preparation of silver salts, silver soldering, and recovery of silver from recycling sources. Grinding of amalgam dyes in dental laboratories and silver nanoparticle-containing spray disinfectants are another source of occupational and consumer exposure (Durán et al., 2017). Waste is generated throughout the process from manufacture to disposal, which may be released and accumulate in the environment increasing the probability of human and eco-toxicity (Hadrup et al., 2020).

The increased use of AgNPs causes major exposure to the environment and human health. However, our knowledge of the human health effects and environmental concentrations of engineered nanoparticles is incomplete (Baun et al., 2017). Ag-NPs may be toxic against mammals, invertebrates or microorganisms. Although, the mechanism of AgNPs-induced toxicity is still unclear (Wu and Tang, 2018). Therefore, exhaustive research is needed into their toxicity in living organisms and also their environmental behavior and fate (Tortella et al., 2020).

Nanoparticles can either intentionally or non-intentionally enter the body through the inhalation, water and food intake, skin uptake, intravenous injection, or implantation. Ag-NPs can accumulate and precipitate in different organs of 
human body with potential for induction of cytotoxicity. Susceptible tissues include liver, spleen, brain, heart, lungs, kidneys, and testicles tissues, as well as it leads to significant change in sperm quality and quantity, and blood brain barrier (BBB) permeability (Moradi-Sardareh et al., 2018).

By the higher chemical reactivity of Ag-NPs due to their large surface area to volume ratio, formation of reactive oxygen species (ROS) within cells greatly increases with subsequent cellular damage (Flores-López et al., 2019).

Medicinal plants have gained tremendous interest of various researchers as an alternative, cheap and easily accessible regimen for the treatment of oxidative stress-related diseases. Aloe vera (Aloe barbadensis Miller) can be rightly considered as a plant of interest (Radha and Laxmipriya, 2015).

Aloe vera, a succulent perennial and drought resisting plant, belonging to the Liliaceae family, has been well known for its therapeutic potential. The parenchyma of the leaves contains a transparent mucilaginous gel known as the aloe vera gel (Akaberi et al., 2016 and Tabatabaei et al., 2017). The gel contains 99 to $99.5 \%$ water. The rest of $0.5-1 \%$ is a fantastic amalgam of anthraquinones, glycoproteins or aloin (important for cathartic activity), polysaccharides, c-glycosylchromone, phenolic compounds, enzymes, hormones, vitamins including vitamin $\mathrm{A}, \mathrm{C}, \mathrm{E}$ and $\mathrm{B} 12$, and minerals such as manganese, zincand selenium which are antioxidants vastly used in medicinal and nutraceutical applications (Rahman et al., 2017 and Debnath et al., 2018).
A wide range of biological effects has been reported for Aloe vera gel, including astringent, hemostatic, immunostimulant, neuroprotective, antidiabetic, antiulcer, antibacterial, anti-inflammatory, antioxidant and anticancer effects. It is also effective in treating gastrointestinal disorders (e.g., constipation, dysentery and diarrhea), radiation injury, wounds, and burns (Kumar et al., 2019).

Consequently, this experimental study was designed to assess the probable protective and/or curative role of crude aloe vera gel extract against AgNPsinduced biochemical, functional and lung cytotoxicity in adult male albino rats.

\section{MATERIALS AND METHODS}

Animals: Thirty-six adult male Wistar albino rats of a local strain weighing 180 $\pm 20 \mathrm{~g}$ and aged approximately 12-16 weeks were chosen for the current study. Rats were purchased from Helwan breeding farm, Helwan, Egypt. Animals were settled under normal laboratory conditions with a room temperature of 25 $\pm 2^{\circ} \mathrm{C}$, the humidity of $(54 \pm 5 \%)$ and alternating light/dark cycles in conventional clean properly ventilated wire-mesh cages $(25 \times 30 \times 25 \mathrm{~cm}-3$ rats per cage) at the animal house, Faculty of Medicine (Boys), Al-Azhar University, Cairo, Egypt. Rats were acclimated for one week for adaptation before beginning the experiment. They were fed on a normal chow diet and allowed free access to water throughout the experiment. All the ethical protocols for the experimental use of laboratory animals were carried out after the approval of the Faculty of 


\section{Mona Mohamed Abd El-Galil and Ahmad Mohammad Farag Alkot}

Medicine (Boys) Institutional Research Board (FMB-IRB), Al-Azhar University, Cairo, Egypt.

Silver nanoparticles (GNPs): Chemical Abstracts Service number "CAS-No. 7440-22-4" with a particle size less than $100 \mathrm{~nm}$ contain $99.9 \%$ trace metals basis in $1 \mathrm{~g}$ glass bottle packaging was purchased from Sigma-Aldrich Chemicals, Cairo, Egypt. Each 100 mg Ag-Nps dispersed in $5 \mathrm{ml}$ of normal saline and was given intraperitoneally (i.p) at a dose of $100 \mathrm{mg} / \mathrm{kg} / \mathrm{day}$, for 4 consecutive weeks (Ahmed et al., 2017).

Nanoparticle characterization: To study the particles size and morphology, the aqueous dispersion of the nanoparticles was drop-cast onto a carbon- coated copper grid (Lee et al., 2013 and Amin et al., 2015). The grid was air dried at room temperature. The mean size and morphology of these Ag-NPs were determined by the transmission electron microscope (TEM) (JEOL JEM-2100; Tokyo, Japan) at the electron microscope research unit, Regional Center for Mycology and Biotechnology (RCMB), Al-Azhar University, Egypt. Examination of the prepared Ag-NPs by TEM revealed spherical and ovoid morphology, and good particle dispersion with average size of $25.18 \pm 10.2 \mathrm{~nm}$. Different shapes of Ag- NPs were also observed (Figure 1).

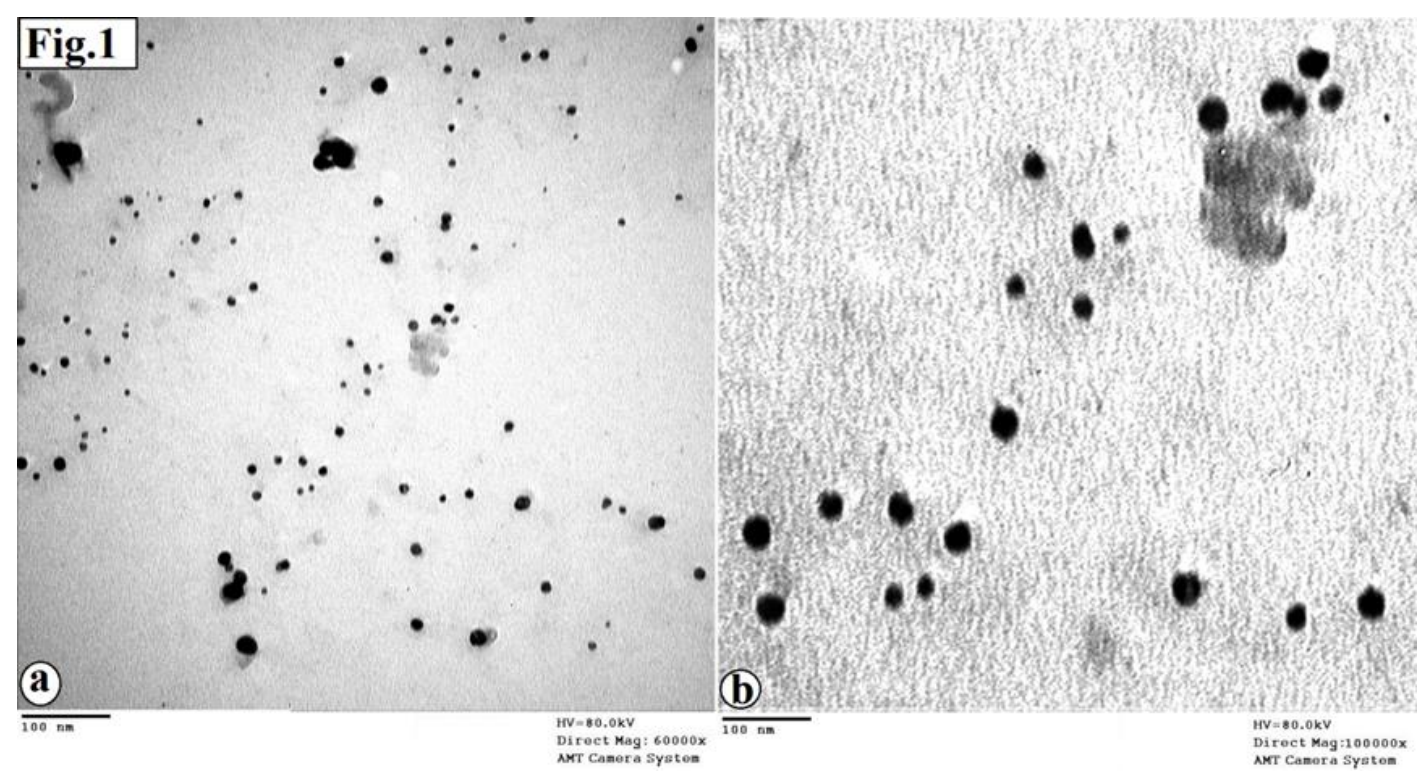

Figure (1): An electron photomicrograph showing spherical and ovoid Ag-Nps distributed homogeneously (TEM ax 60000 and b x100000, Scale bar=100nm).

Aloe vera gel extract preparation: Aloe vera plant with leaves between 40 and 60 $\mathrm{cm}$ in length were rinsed with clean water to remove debris and sand, and thereafter, dried with a clean piece of cloth. Fresh leaves were cut longitudinally from the middle to expose the gel. AV solid gel in the center of the leaf was collected and was gently homogenized into an electric blender to shatter the block resulting mucilaginous, thick and straw colored homogenate was obtained. The dose of the crude gel extract used for the present 
study was $0.4 \mathrm{ml} / 100 \mathrm{~g}$ body weight orally by gastric tube (Akpan et al., 2014 and Nna et al., 2014).

Experimental design: Rats were equally dispensed into five groups:

- Group I (control group): Twelve rats were subdivided equally into two subgroups: subgroup IA, were kept on chow diet and allowed free access to water without any treatment throughout the whole period of the experiment and subgroup IB received $1 \mathrm{ml}$ of normal saline $0.9 \%$ (Ag NPs solvent) by intraperitoneal injection once daily, for 4 weeks and then rats were sacrificed.

- Group II (Ag-NPs injected group): Six rats received Ag-NPs intraperitoneally (i.p) at a dose of 100 $\mathrm{mg} / \mathrm{kg} /$ day for 4 consecutive weeks and then they were sacrificed.

- Group III (combined Ag-NPs and Aloe vera-treated group): Six rats received aloe vera gel $(0.4 \mathrm{ml} / 100$ gm) orally by gastric tube one hour before intraperitoneal injection of AgNPs solution by the same dose and duration as group II.

- Group IV (Recovery group): Six rats received Ag-NPs intraperitoneally (i.p) at a dose of $100 \mathrm{mg} / \mathrm{kg} /$ day for 4 consecutive weeks then left with no further treatment for another 4 weeks.

- Group V (Aloe vera-treated group post to Ag-NPs): Six rats received Ag-NPs intraperitoneally (i.p) at a dose of $100 \mathrm{mg} / \mathrm{kg} /$ day for 4 consecutive weeks, and then received Alo vera gel extractat a dose of $0.4 \mathrm{ml}$ /100 gm orally by gastric tube along with basal diet daily for another 4 weeks.

All rats were weighed individually at the beginning of the experimental protocol, and at the end, just before collecting samples.

At the end of the experiment, animals were overnight fasted, blood samples were withdrawn from retro-orbital sinuses by capillary tubes under ether anesthesia, centrifuged at 3000 round per minute to separate the serum that was maintained in a freezer at $-80^{\circ} \mathrm{C}$ until further analyses for:

- Total antioxidant capacity "TAC" (mMol/L).

- Malondialdehyde "MDA" (ng/L).

- Tumor necrotic factor-alpha "TNF- $\alpha "(\mathrm{pg} / \mathrm{ml})$.

- Interleukin 6 "IL-6" (pg/ml).

TAC was estimated by the conventional colorimetric method using Quanti Chrom TM assay kits (Biodiagnostic Company, Egypt) according to the manufacturer's instruction. The MDA was measured in serum by TBA method using colorimetric assay kit (Elabscience Biotechnology Inc., China) (Malek-Mohammadi et al., 2015). The levels of TNF- $\alpha$ and IL-6 were determined using a rat-specific, commercially available enzyme-linked immunosorbent assay (ELISA) kit (BioSource International Inc., California, USA) according to the manufacturer's instructions (Kafi et al., 2015). These biochemical studies were done in El Nour Global Lab, Cairo, Egypt.

Immediately after the rats were anesthetized by ether inhalation and blood 


\section{Mona Mohamed Abd El-Galil and Ahmad Mohammad Farag Alkot}

samples were taken, a median sternotomy was performed. Lungs were rapidly dissected out from the thoracic cavity. Samples from the right lung were immediately fixed in $10 \%$ buffered formalin for 72 hours, dehydrated in ascending grades of ethyl alcohol, followed by clearance in xylene, impregnation and embedding in paraffin wax to obtain paraffin blocks. Sections of $5 \mu \mathrm{m}$ thickness were cut using a rotary microtome (LEICA RM 2125; UK), mounted on clean glass slides, and stained with the following (Bancroft and Layton, 2013):

- Hematoxylin and Eosin (H\&E) for studying the general histological structure.

- Mallory Trichrome for staining the collagen fibers.

- Periodic Acid- Schiff (PAS) reaction to quantify the number of mucus-secreting goblet cells and mucus expression along bronchial epithelial lining.

The immunohistochemical
technique was used to detect the
oxidative stress marker, inducible nitric
oxide synthase (iNOS) (Yang et al., 2020),
and to evaluate the alveolar macrophages
CD-68 expressions (Ramos-Vara et al.,
2008) in formalin-fixed lung sections
using an avidin-biotin-peroxidase
complex immunohistochemical technique.
Briefly, positively charged paraffin
sections of 5- $\mu$ m thickness were dewaxed
in xylene, rehydrated in descending grades
of ethanol. Heat-induced antigen retrieval

by microwaving was performed using citrate buffer $\mathrm{pH} 6.0$ (10 Mm, $20 \mathrm{~min})$. Endogenous peroxidase was blocked by immersion lung sections in $0.3 \% \mathrm{H} 2 \mathrm{O} 2$ for $30 \mathrm{~min}$ and then sections were incubated overnight at $4^{\circ} \mathrm{C}$ with primary antibody recognizing iNOS (rat monoclonal antibody, 1:500 dilution, Transduction Laboratories, San Diego, California, USA) and CD-68 antibody (mouse monoclonal antibody, 1:200 dilution, code NCL-L-CD68; Leica Biosystems, Benton La, Newcastle Ltd, UK) in a humidified chamber according to the manufacturer's instructions. The sections were incubated with biotinylated antirabbit or antimouse immunoglobulins (Dako Ltd, diluted 1:200) for the corresponding primary antibody and thereafter sections were incubated with the avidin-biotin-conjugated peroxidase complex (Vector Laboratories Ltd. UK). The colorimetric detection of peroxides was developed using $0.05 \%$ diaminobenzidine tetra-hydro chloride (DAB) substrate chromogen solution (Sigma Chemical Co., Poole, UK) for 15 min until the desired brown color obtained. Finally, sections were counterstained with Mayer's hematoxylin, dehydrated and mounted with DPX. A cell with a brown cytoplasm and / or with a brown nucleus was considered immunoreactive (Figures 2b, 3b). Negative controls were processed by replacing the primary antibody with phosphate-buffered saline (PBS) (Figures 2a, 3a). 


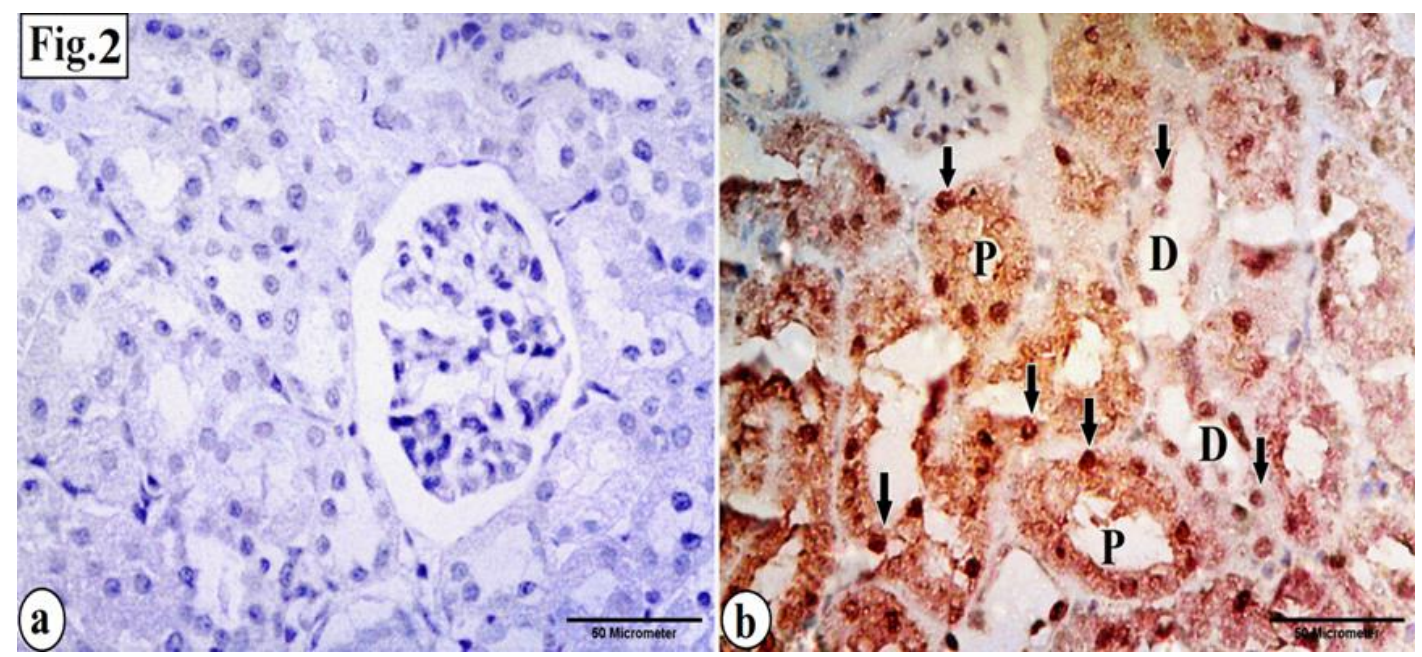

Figure (2): A photomicrograph of iNOS staining in the renal tissue sections: (a) primary antibody is omitted (negative control). (b) Positive immunohistochemical staining showing iNOS positive reaction (black arrows) in the cytoplasm and nuclei of cells lining proximal (p) and distal (D) convoluted tubules after secondary antibody. (Anti iNOS immunoreaction, $x$ 400, Scale bar; $50 \mu \mathrm{m})$.

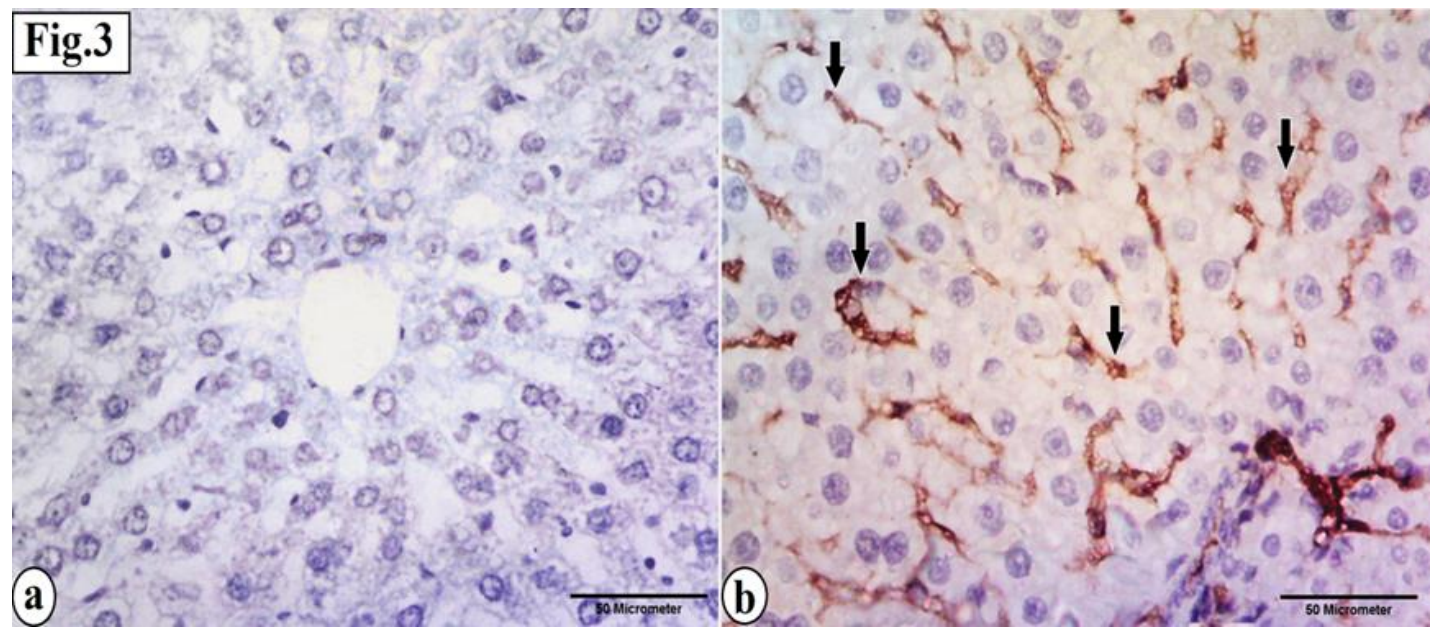

Figure (3): A photomicrograph of anti-CD-68 immune expression in the liver tissue sections: (a) primary antibody is omitted (negative control). (b) Positive immunohistochemical staining showing CD-68 positive reaction in the cytoplasm of Kupffer cells (black arrows) inside the blood sinusoids and infiltrated between hepatocytes after secondary antibody. (Anti CD-68 immunoreaction, x 400, Scale bar; 50 $\mu \mathrm{m}$ ).

Histo-morphometric measurements: All sections were examined, photographed by Leica DM2500 optical microscopes (Leica microsystems, Nussloch, Germany) coupled to a Leica ICC50 W digital camera, and transferred to the screen using a computerized image analyzer Leica Q500 MC program (Leica Microsystems Ltd, Cambridge, UK). The data were calibrated automatically to convert the measurement units (pixels) produced by the image analyzer program 


\section{Mona Mohamed Abd El-Galil and Ahmad Mohammad Farag Alkot}

into actual micrometer units. Ten different non-overlapping randomly selected fields from five different lung sections in each group, were examined to quantitatively evaluate the following:

- The thickness of the interalveolar septa in H\&E stained section at X 400 magnification (Jensen, 2013).

- The mean area percentage of the green stained collagen fibers $/ \mu \mathrm{m} 2$ within the lung interstitium and perivascular around the pulmonary blood vessels in Mallory trichrome-stained sections at X 200 magnification (Jensen, 2013).

- The mean percentage of PAS-positive goblet cells per bronchiole (number of PAS-positive goblet cells divided by the total epithelial cell number along the basement membrane of randomly selected transversely cut large sized bronchiole defined by having approximately 150-200 luminal airway epithelial cells) in PAS stained sections at X 400 magnification (Belikoff et al., 2012).

- The mean area percentage of positive iNOS immunoreactivity in anti-iNOS immune-stained sections was estimated at X 400 magnification
(Abdel-Dayem et al., 2014 and Yang et al., 2020).

- The mean count of alveolar macrophages in anti CD-68 immunostained sections in at X 400 magnification was assessed (RamosVara et al., 2008 and Nouno et al., 2019).

All histomorphometric measurements were carried out at the Regional Center for Mycology and Biotechnology (RCMB), Al-Azhar University, Cairo, Egypt.

Statistical Analysis: Most of the obtained data were statistically expressed as means \pm standard deviation (mean \pm SD), and compared using the one-way analysis of variance (ANOVA) followed by Tukey's post hoc test. A level of probability (Pvalue) less than 0.05 was considered statistically significant. Spearman's correlation coefficient (R) was used to evaluate the linear association between studied parameters. Statistical analysis was performed using the Statistical Package for the Social Sciences Software, Version 20 for Windows (SPSS Inc., Chicago, Illinois, USA). 


\section{RESULTS}

There was a statistically insignificant change among the two control subgroups $(p>0.05)$ in all parameters. Therefore, all comparisons were referred to the control group with neglecting its subgrouping.

Effect on the body weight: The mean values of initial body weight among rats of all experimental groups were nearly similar with no significant difference $(\mathrm{P}>0.05)$. At the end of the experiment, Ag-NPs injected (GII) and the recovery (GIV) groups showed nearly similar mean values $(\mathrm{P}>0.05)$ with a significant decrease in the final body weight as compared to the control rats $(\mathrm{P}<0.001)$. The final body weight remained nearly as the control in the combined Aloe vera gel + Ag-NPs group (III), and they were significantly higher than those in GII. Also, aloe vera gel-treated group (V) recorded a statistically significant increase in the final body weight when compared to the Ag-NPs (GII) and recovery (GIV) groups $(\mathrm{P}<0.001)$, but this value didn't return to normal and revealed a significant difference when compared to the control group $(\mathrm{P}<0.05)$ (Table 1).

Table (1): One-way ANOVA followed by post hoc Tukey's comparative statistical analysis of the mean initial, and final body weight (BW) in rats of different groups

\begin{tabular}{|c|c|c|c|c|c|c|}
\hline $\begin{array}{l}\text { Studied groups } \\
\text { Parameters }\end{array}$ & $\begin{array}{c}\text { Control } \\
(\mathbf{n}=\mathbf{6})\end{array}$ & $\begin{array}{c}\text { Ag NPs- } \\
\text { injected } \\
(\mathrm{n}=6)\end{array}$ & $\begin{array}{c}\text { Aloe vera gel } \\
+ \text { Ag NPs } \\
(n=6)\end{array}$ & $\begin{array}{c}\text { Recovery } \\
\text { group } \\
(\mathbf{n}=6)\end{array}$ & $\begin{array}{c}\text { Aloe vera gel } \\
\text { treated } \\
(\mathrm{n}=6)\end{array}$ & $P$ \\
\hline $\begin{array}{c}\text { Initial BW } \\
(\mathrm{g})\end{array}$ & $190.5 \pm 9.6$ & 192. & $189.6 \pm 9.2$ & $188.3 \pm 10.3$ & \pm 10.2 & $>0.05$ \\
\hline $\begin{array}{c}\text { Final BW } \\
(\mathrm{g})\end{array}$ & $235 \pm 6.5$ & $162.2 \pm 8.5^{\mathrm{a}^{*}}$ & $228.2 \pm 7.3^{b^{*}}$ & $167 \pm 4.8^{\mathrm{a}^{*}}$ & $209.5 \pm 5.4^{a^{*} b^{*} c^{*}}$ & $<0.001$ \\
\hline
\end{tabular}

All results were expressed as mean \pm SD; $S D$ : standard deviation; $n$ : number of rats.

${ }^{a}$ significant versus control group

bsignificant versus AgNPs-injected group

${ }^{c}$ significant versus recovery group

Effect on serum TAC, TNF- $\alpha$, IL-6 and MDA: Ag-NPs treated group (II) revealed a significant decrease in the total antioxidant capacity (TAC) coupled with a significant increase in malondialdehyde (MDA), tumor necrotic factor-alpha (TNF- $\alpha$ ) and interleukin 6 (IL-6) when compared to the control rats $(\mathrm{P}<0.001)$. Inversely, Aloe vera gel extract improved all these markers as demonstrated by a significant increase in TAC, coupled with a significant decrease in TNF- $\alpha$, MDA and IL-6 in both groups III and V when compared to Ag-NPs injected group $(\mathrm{P}<$ $0.001)$. The values of all these parameters were close to normal in the combined aloe vera and $\mathrm{Ag}$-NPs group (III) $(\mathrm{P}>0.05$ in comparison to the control group) but remained significantly differ than control in the Aloe vera-treated group (V) which showed at the same time significant variations when compared with GIV $(\mathrm{P}<0.05)$ (Table 2). 


\section{Mona Mohamed Abd El-Galil and Ahmad Mohammad Farag Alkot}

Table (2): One-way ANOVA followed by post hoc Tukey's comparative statistical analysis of the serum antioxidant asseys (TAC \& MDA) and proinfilammatory cytokines (TNF- $\alpha$ \&IL-6) in the different studied groups.

\begin{tabular}{|c|c|c|c|c|c|c|}
\hline $\begin{array}{l}\text { Studied groups } \\
\text { Parameters }\end{array}$ & $\begin{array}{c}\text { Control } \\
(n=6)\end{array}$ & $\begin{array}{c}\text { Ag NPs- } \\
\text { injected } \\
(n=6)\end{array}$ & $\begin{array}{c}\text { Aloe vera gel } \\
+ \text { Ag NPs } \\
(n=6)\end{array}$ & $\begin{array}{l}\text { Recovery } \\
\text { group } \\
(\mathbf{n}=6)\end{array}$ & $\begin{array}{c}\text { Aloe vera gel } \\
\text { treated } \\
(n=6)\end{array}$ & $\boldsymbol{P}$ \\
\hline $\begin{array}{c}\text { TAC } \\
(\mathrm{mM} / \mathrm{L})\end{array}$ & $1.1 \pm 0.1$ & $0.41 \pm 0.09^{a^{*}}$ & $0.93 \pm 0.21^{b^{*} c^{*}}$ & $0.53 \pm 0.07^{a^{*}}$ & $0.82 \pm 0.1^{\mathrm{a} * \mathrm{~b}^{*} \mathrm{c}^{*}}$ & $<0.001$ \\
\hline $\begin{array}{l}\text { MDA } \\
\text { (ng/L) }\end{array}$ & $0.9 \pm 0.1$ & $3.7 \pm 0.4^{\mathrm{a}^{*}}$ & $0.81 \pm 0.2^{b^{*} c^{*}}$ & $2.9 \pm 0.6^{a^{*}}$ & $0.72 \pm 0.1 \mathrm{a}^{\mathrm{a} * \mathrm{~b}^{*} \mathrm{c}^{*}}$ & $<0.001$ \\
\hline $\begin{array}{l}\text { TNF- } \alpha \\
(\mathrm{pg} / \mathrm{ml})\end{array}$ & $161.1 \pm 2.8$ & $245.6 \pm 7.3^{a^{*}}$ & $167.4 \pm 6.2^{b * c^{*}}$ & $259.3 \pm 11.2^{\mathrm{a}^{*}}$ & $176.2 \pm 5.4^{\mathrm{a}^{*} \mathrm{~b}^{*} \mathrm{c}^{*}}$ & $<0.001$ \\
\hline $\begin{array}{c}\text { IL-6 } \\
\text { (pg/ml) }\end{array}$ & $64.7 \pm 1.5$ & $113.4 \pm 2.7^{a^{*}}$ & $72.2 \pm 2.1^{b^{*} c^{*}}$ & $101.3 \pm 11.2^{a^{*}}$ & $80.2 \pm 3.4^{\mathrm{a}^{*} \mathrm{~b}^{*} \mathrm{c}^{*}}$ & $<0.001$ \\
\hline
\end{tabular}

All results were expressed as mean \pm SD; SD: standard deviation; n: number of rats; Ag-NPs: Silver nanoparticles; TAC: Total antioxidant capacity; MDA: malondialdehyde; TNF- $\alpha$ : tumour necrotic factor-alpha; IL-6: interleukin 6.

${ }^{\mathrm{a}}$ significant versus control group

${ }^{\mathrm{b}}$ significant versus AgNPs-injected group

${ }^{\mathrm{c}}$ significant versus recovery group

There was a significant negative correlation between TAC and MDA with a correlation factor -0.898 (Figure 4).

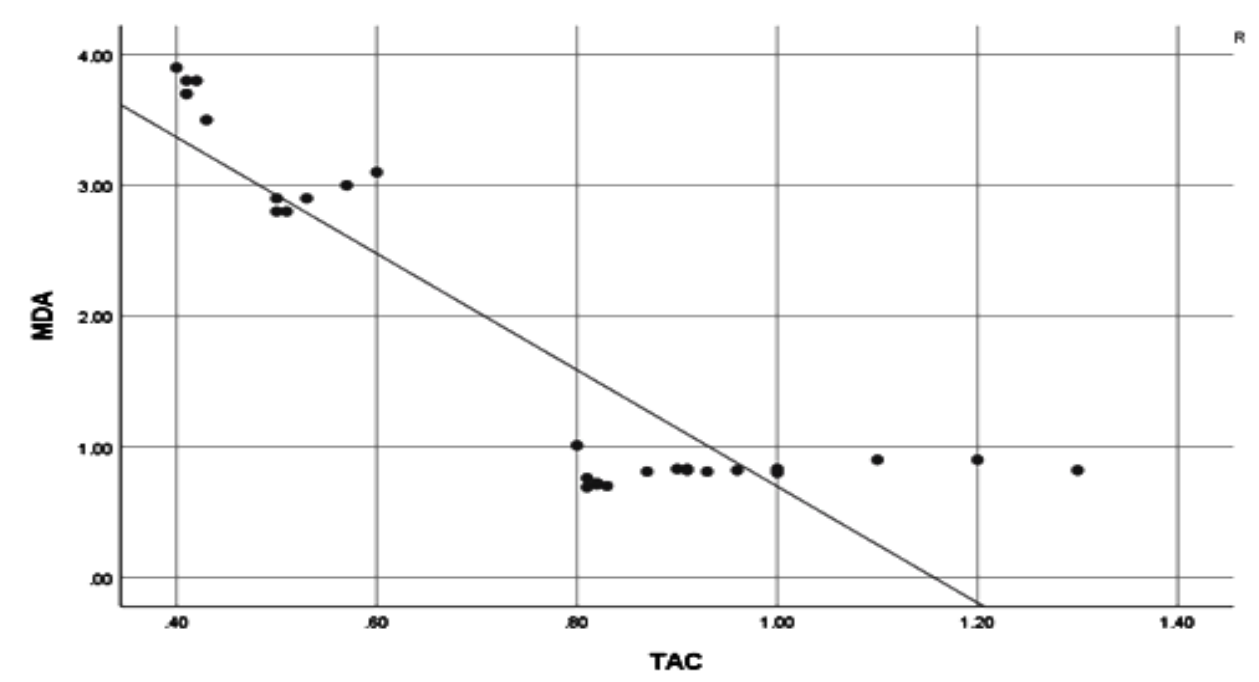

Figure (4): The correlation between MDA and TAC 
There was a significant positive correlation between TNF $\alpha$ and IL- 6 with a correlation factor 0.936 (Figure 5).

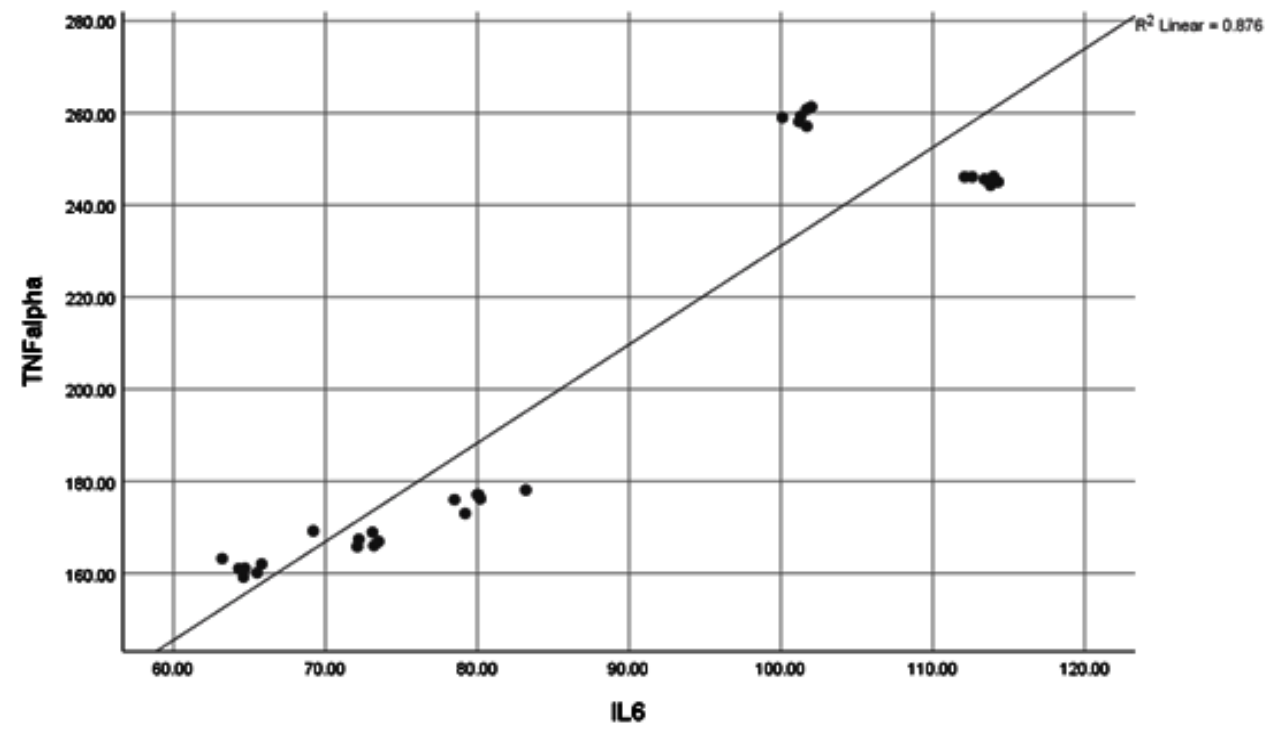

Figure (5): The correlation between TNF- $\alpha$ and IL-6

As regard the relation between the oxidative stress and the inflammatory state, there was a significant positive correlation between MDA and TNF- $\alpha$ with a correlation factor 0.937 and between MDA and IL-6 with a correlation factor 0.947 (Figure 6).

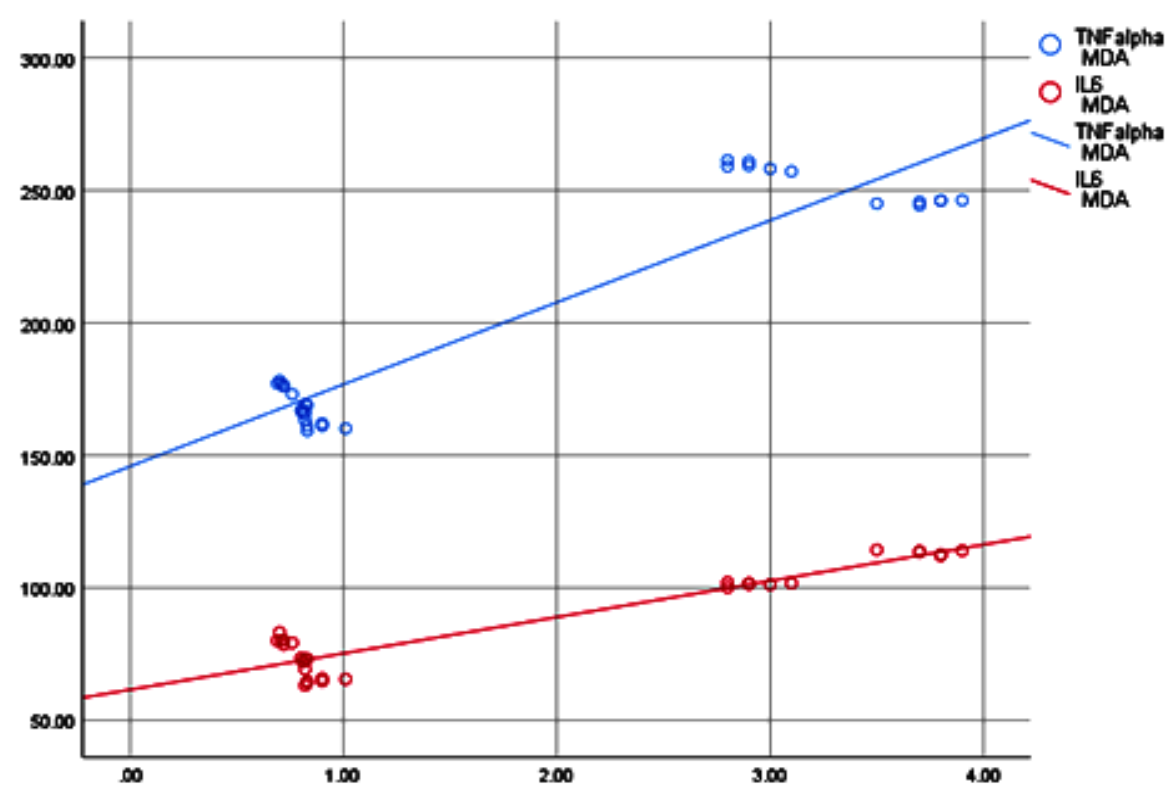

Figure (6): The correlation between MDA, TNF- $\alpha$ and IL-6 


\section{Mona Mohamed Abd El-Galil and Ahmad Mohammad Farag Alkot}

Also, the body weight showed a significant negative correlation with oxidative stress and inflammatory cytokines. The correlation factor (R) between body weight and MDA was -
0.929. The correlation factors between body weight \& TNF- $\alpha$ and between body weight \& IL-6 were -0.965 and -0.975 respectively (Figure 7).

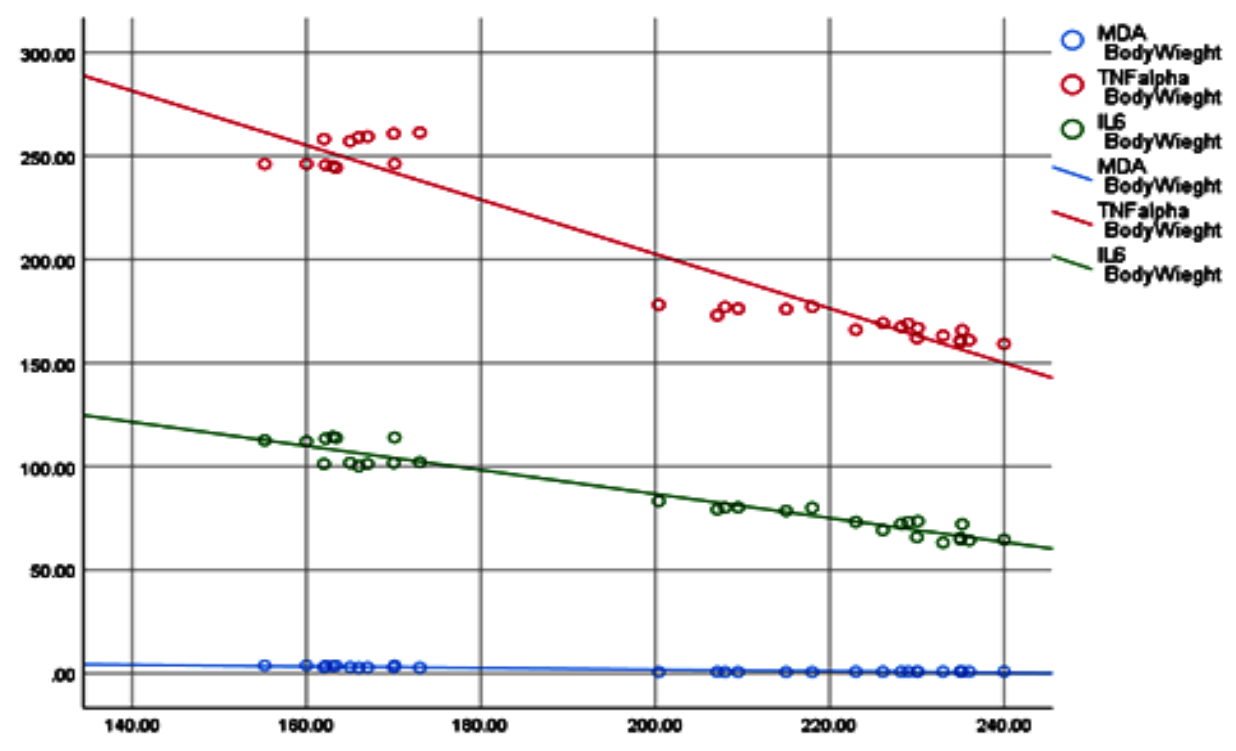

Figure (7): The correlation between final body weight \& MDA, TNF- $\alpha$ and IL-6

\section{Histological and immunohistochemical results:}

Hematoxylin and Eosin (H\&E) stained sections of lung tissue of the control group revealed normal spongy histological architecture of the lung tissue with variable sized polygonal clear patent alveoli separated by thin interalveolar septa, alveolar sacs, a patent bronchiole intermixed with the alveoli and lined with simple columnar epithelium, surrounded by few layers of smooth muscles and connective tissue lamina. The alveoli and alveolar sacs were mostly lined by squamous type I pneumocytes with flattened nuclei and a few large- sized cuboidal type II pneumocytes with rounded nuclei bulging into the alveolar lumen. Interstitial cells appeared in the thin interalveolar septa (Figures 8a, 8b)
Lung sections in the combined Aloe vera gel $+\mathrm{Ag}$-NPs group (III) exhibited a high similarity to the normal alveolar pattern in comparison to the control group, despite few inflammatory cells studded the pulmonary blood vessels (Figures 9a, 9b).

Inversely, $H \& E$ stained lung sections of the AgNPs-injected (GII) and the recovery groups (IV) revealed severe histopathological alterations in the form of destructed narrowed and collapsed alveoli with marked thickening of the interalveolar septa, multiple large areas of hemorrhage along with extravasated red blood corpuscles (RBCs) within the lung interstitium and in the alveolar lumen. Thick dilated congested inter-alveolar pulmonary capillaries, as well as diffuse lymphocytic inflammatory cellular 
infiltrations, were frequently detected within the lung interstitium. Moreover, many large alveolar macrophages with vacuolated cytoplasm accumulated in the pulmonary interstitium and within the alveolar lumen. Detached cellular debris with shrunken darkly stained nuclei was also noticed in the bronchiolar lumen (Figures 10a-10d, 11a-11d).

Partial improvement of the lung histoarchitecture was noticed in the Aloe vera gel-treated group $(\mathrm{V})$ where the lung parenchyma restored the usual organization in the form of normal bronchioles intermixed with the alveoli more or less similar to that of the control, despite thickening of interalveolar septa in some regions as well as congested blood vessels studded with few lymphocytes and a few extravasated RBCs were detected in comparison to the Ag-NPs group (Figures 12a, 12b). 


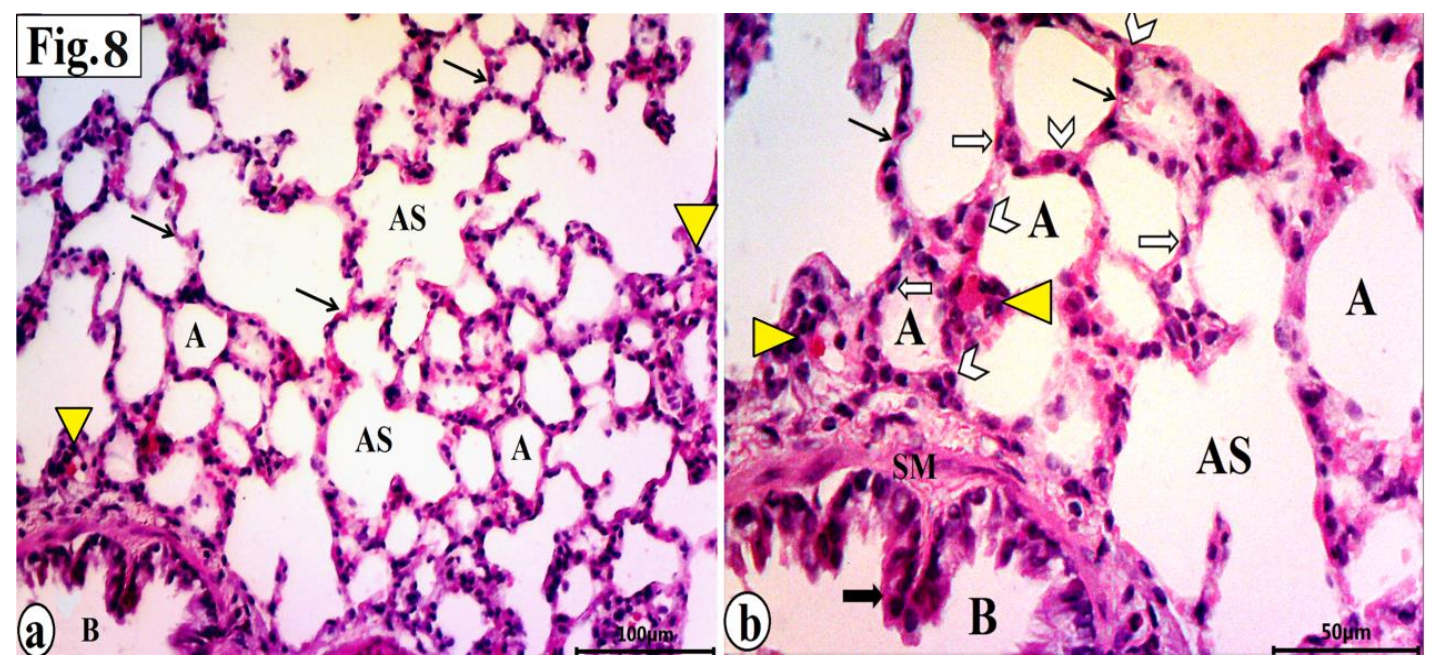

Figure (8): Photomicrographs of the rat lung from the control group showing: (a, b) Normal alveoli (A), thin interalveolar septa (thin black arrow), alveolar sacs (AS), pulmonary blood vessel (yellow arrow heads) and bronchiole (B). (b) A higher magnification showing: alveoli are lined by squamous type I pneumocyte with flattened nuclei (transverse white arrow) and cuboidal type II pneumocytes with rounded nuclei (bifid arrow head). Bronchiole (B) is lined with simple columnar epithelium (thick black arrow) and is surrounded by smooth muscle layer (SM) and connective tissue lamina (H\&E a x 200, Scale bar $=100 \mu \mathrm{m} ;$ b x400, Scale bar $=50 \mu \mathrm{m})$.

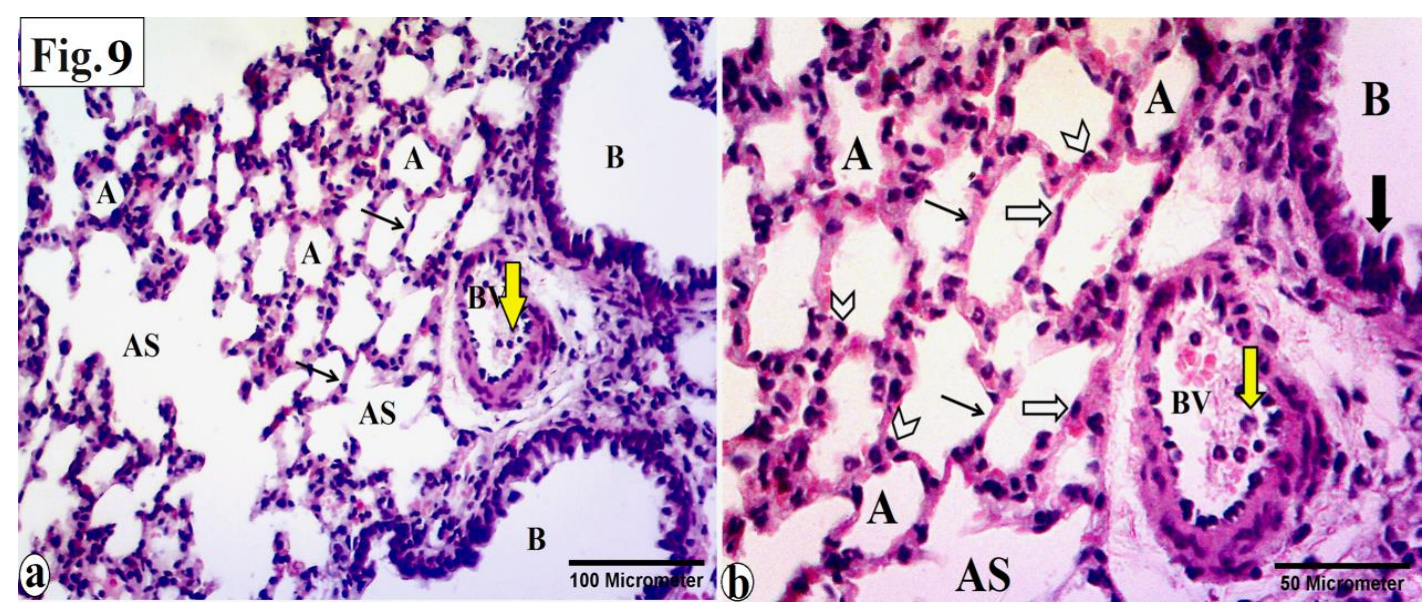

Figure (9): Photomicrographs of the rat lung from the combined Aleo vera and AG-NPs group showing: (a, b) Normal alveoli (A), thin interalveolar septa (thin black arrow), alveolar sacs (AS), bronchiole (B). Pulmonary blood vessel (BV) is studded with few inflammatory cells (yellow arrow). (b) A higher magnification showing: alveoli are lined by squamous type I pneumocytes with flattened nuclei (trasverse white arrow) and cuboidal type II pneumocytes with rounded nuclei (bifid arrow head) bulging into the alveolar lumen. Bronchiole (B) is lined with simple columnar epithelium (thick black arrow) (H\&E a x 200, Scale bar $=100 \mu \mathrm{m}$; b x400, Scale bar $=50 \mu \mathrm{m})$. 


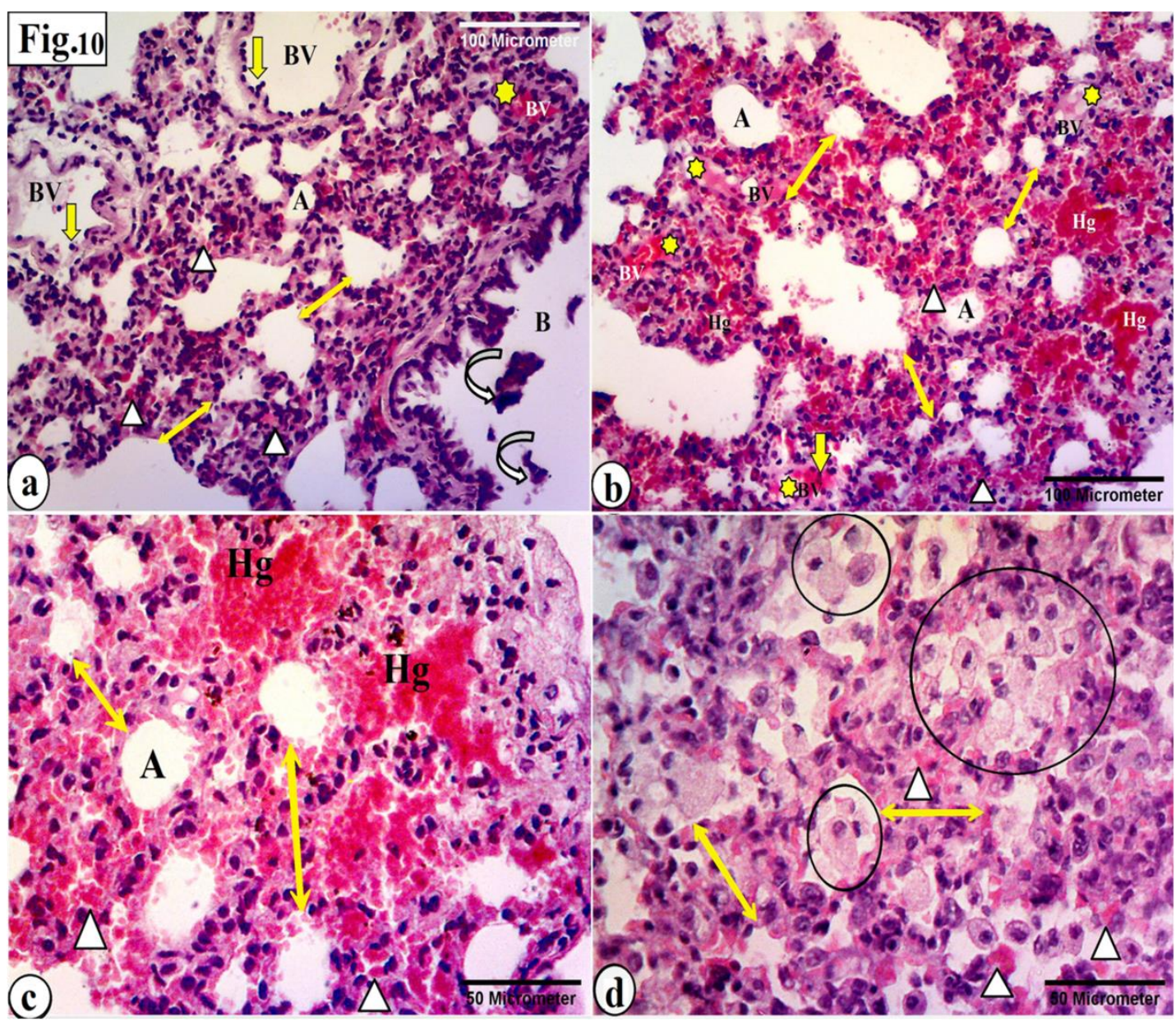

Figure (10): Photomicrographs of the rat lung from the Ag NPs- injected group showing: (a-d) Narrowed alveolar spaces (A), thick interalveolar septa (double head arrows) and extravasated red blood corpuscles (white arrow heads) within the lung interstitium. (a) Detached cells with darkly stained nuclei (curved arrows) in the bronchiolar lumen (B). (a, b) Congested (yellow stars) pulmonary blood vessels (BV) with lymphocytic infiltration (yellow arrows). (b, c) Multiple, large areas of hemorrhage $(\mathrm{Hg})$ as well as extravasated red blood corpuscles (white arrow heads). (d) Large alveolar macrophages (circles) with vacuolated acidophilic cytoplasm in the pulmonary interstitium and within the alveolar lumen as well as extravasated red blood corpuscles (white arrow heads) (H\&E a, b x200, Scale bar $=100 \mu \mathrm{m}$; c and d x400, Scale bar $=50 \mu \mathrm{m})$. 


\section{Mona Mohamed Abd El-Galil and Ahmad Mohammad Farag Alkot}

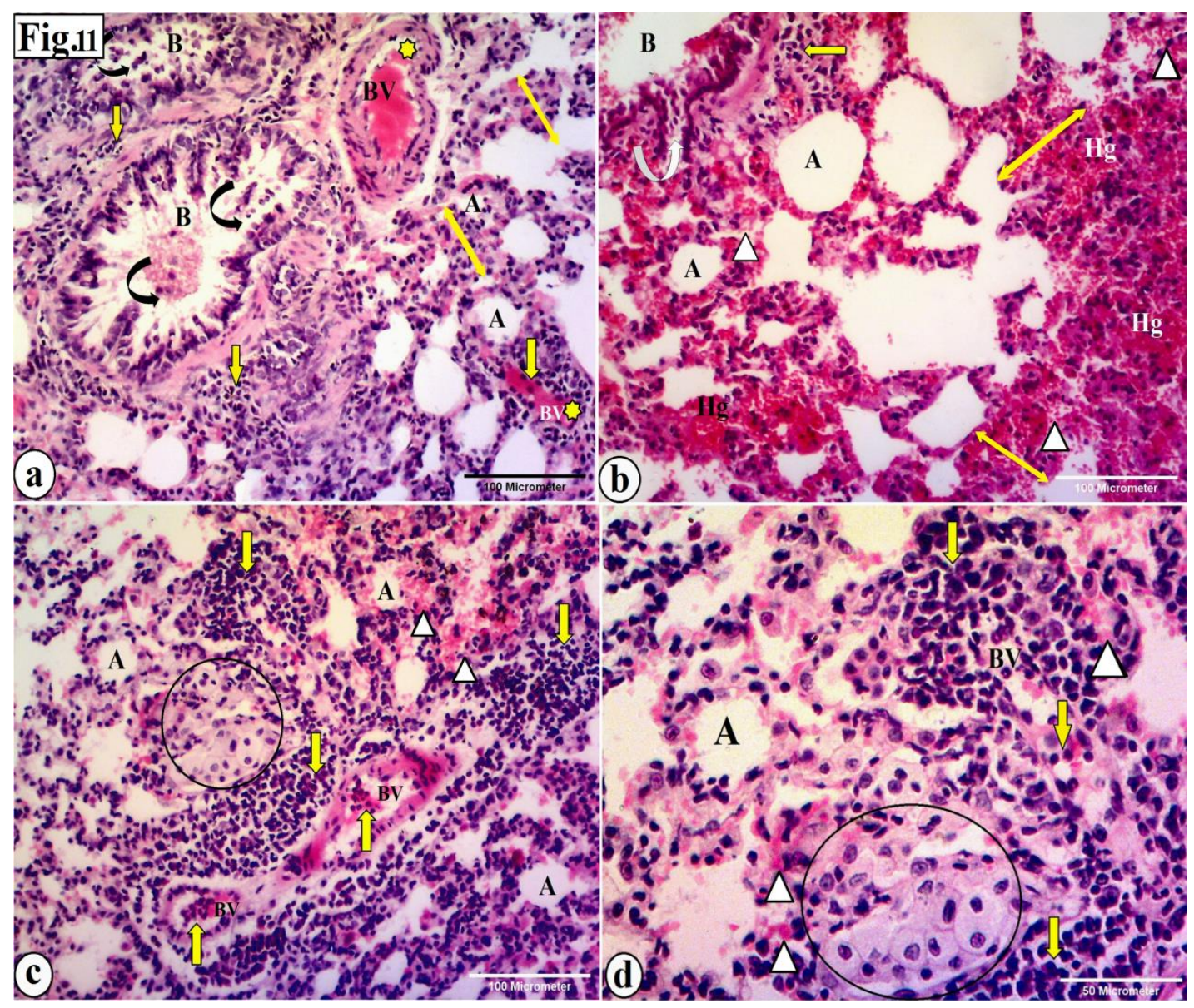

Figure (11): Photomicrographs of the rat lung from the recovery group showing: $(a, b)$ Narrowed alveolar spaces (A), thick interalveolar septa (double head arrow) and detached cells with darkly stained nuclei (curved arrows) in the bronchiolar lumen (B). (a) Thick congested (yellow stars) pulmonary blood vessels (BV) with lymphocytic infiltration (yellow arrows). (b) Multiple, large areas of hemorrhage $(\mathrm{Hg})$ and extravasated red blood corpuscles (white arrow heads) within the lung interstitium. (c, d) Extravasated red blood corpuscles (white arrow heads) and extensive lymphocytic infiltration (yellow arrows) in the pulmonary interstitium and surrounding the congested pulmonary blood vessels (BV). Large alveolar macrophages (circles) with vacuolated acidophilic cytoplasm within the lung interstitium are also observed (H\&E a, b, c x200, Scale bar $=100 \mu \mathrm{m} ; \mathbf{d}$ x400, Scale bar $=50 \mu \mathrm{m})$. 


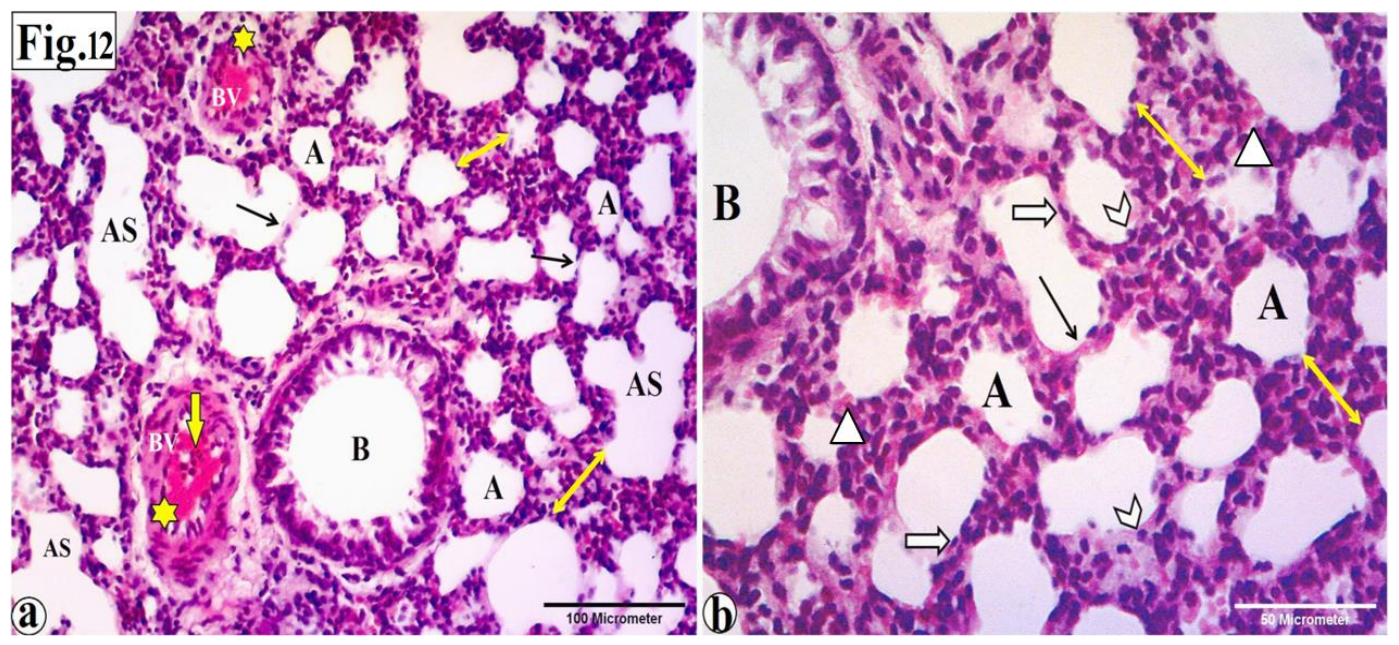

Figure (12): Photomicrographs of the rat lung from the Aleo vera-treated group showing: (a, b) Normal alveoli (A), thin interalveolar septa (black arrow), alveolar sacs (AS) and bronchiole (B). Thick interalveolar septa (double head arrow) in some regions are also observed. (a) Thick congested (yellow stars) pulmonary blood vessel (BV) with few lymphocyte infilteration (yellow arrow). (b) A higher magnification showing: Alveoli (A) are lined by squamous type I pneumocytes with flattened nuclei (transverse white arrow) and cuboidal type II pneumocytes with rounded nuclei (bifid arrow head) bulging into the alveolar lumen. Few extravasated RBCs (white arrow heads) are seen within the lung interstitium (H\&E a x 200, Scale bar $=100 \mu \mathrm{m} ;$ b x400, Scale bar $=50 \mu \mathrm{m})$.

Mallory trichrome stained sections of the control group (I) revealed fine delicate blue collagen fibers of normal density and distribution within the lung interstitium, in the thin interalveolar septa, and perivascular around the wall of the pulmonary blood capillaries and around the bronchiolar wall (Figure 13a). The combined Aloe vera gel + Ag-NPs group (III) was closely similar to the control despite that denser collagen fiber appeared around the congested blood vessels (Figure 13b).

Extensive interstitial fibrosis with an increase in the density and distribution of the collagen fibers within the lung interstitium, in the thick interalveolar septa, around the bronchioles and around the congested pulmonary blood vessels could be detected in the AgNPs-injected group (II) (Figures 13c, 13d) and in the recovery group (IV) (Figure 13e).

On the contrary, there was a nearly normal dispersion of fine collagen fibers in the group $\mathrm{V}$ within the relatively thin interalveolar septa and around the bronchioles that appeared more or less similar to that of the control, despite that denser collagen fiber distributed within the thick regions of interalveolar septa as well as around the congested blood vessels compared to the control group (Figure 13f). 


\section{Mona Mohamed Abd El-Galil and Ahmad Mohammad Farag Alkot}

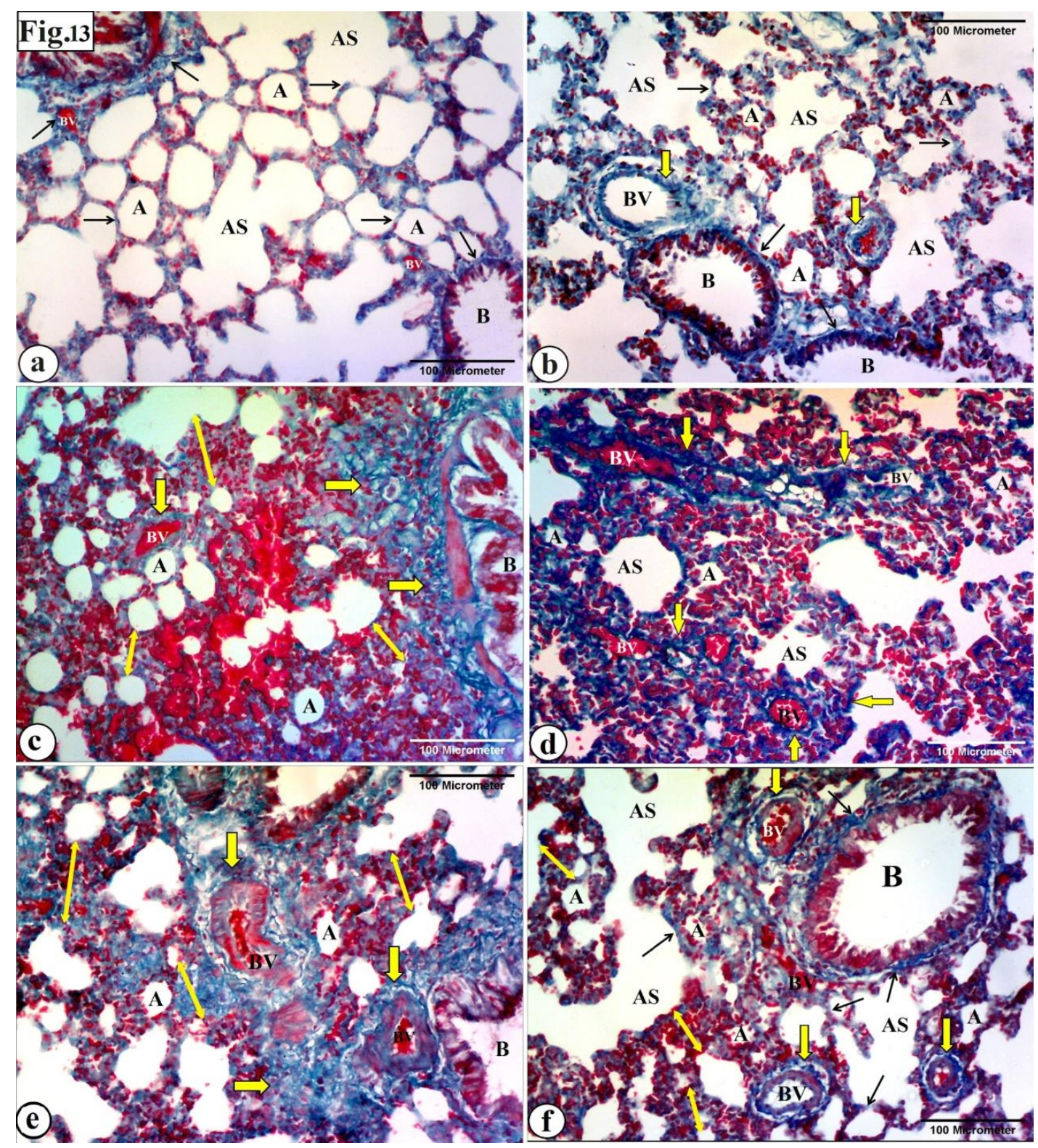

Figure (13): Photomicrographs of the rat lung from all experimental groups: Control group (a) showing: fine collagen fibers within the lung interstitium around the alveolar sacs (AS), in the thin interalveolar septa (black arrow) in between alveoli (A), around the bronchiole (B) and around the pulmonary blood vessels (BV). Combined Aloe vera $+\mathrm{Ag}$ NPs group (b) showing: normal collagen distribution as in the control group with denser collagen fiber (yellow arrow) around the congested blood vessels (BV). Ag-Nps group (c, d) and the recovery group (e) showing: increase in the density and distribution of the collagen fibers in the thick interalveolar septa (double head arrows), in the lung interstitium (yellow arrow) between alveoli (A), around the bronchiole (B) and around the congested blood vessels (BV). Aleo vera-treated group (f) showing: normal distribution of the collagen fibers in the relatively thin interalveolar septa (arrows), in between alveoli (A), alveolar sacs (AS) and around the bronchiole (B) more or less as the control. Denser collagen fibers within the thick regions of interalveolar septa (double head arrow), as well 
as around the congested (yellow arrow) blood vessels (BV) is also observed (Mallory trichrome a-f $x 200$, Scale bar $=100 \mu \mathrm{m})$.

Periodic acid Schiff (PAS) stained sections in the control (GI) and in the combined Aloe vera gel + Ag-NPs group (III) were closely similar. They revealed a few pink-magenta stained cells lined the large-sized bronchioles (Figures 14a, 14b). Few PAS-positive inflammatory cells were also detected in the bronchiolar lumen of the GIII (Figure 14b).

Conversely, in the Ag-NPs injected (GII) and the recovery (GIV) groups, the mucus content was clearly increased in the bronchiolar epithelial lining which was evident by an intense strong PAS reaction with markedly increased goblet cells number concomitant with mucus overproduction in large-sized bronchioles as compared with the control group. PASpositive inflammatory cells were also detected in the bronchiolar lumen (Figures 14c, 14d). There was an intense PAS-positive reaction in the pulmonary blood vessel (Figure 14d).

On the contrary, a marked reduction in PAS-positive mucus-secreting cells was detected in the bronchiolar epithelial lining of the aloe vera-treated group (V) that appeared closely similar to that of the control group without evidence of increased their number. PAS-positive reaction in the pulmonary blood vessel was also observed. Only a few PASpositive inflammatory cells were detected in the bronchial lumen (Figure 14e). 


\section{Mona Mohamed Abd El-Galil and Ahmad Mohammad Farag Alkot}

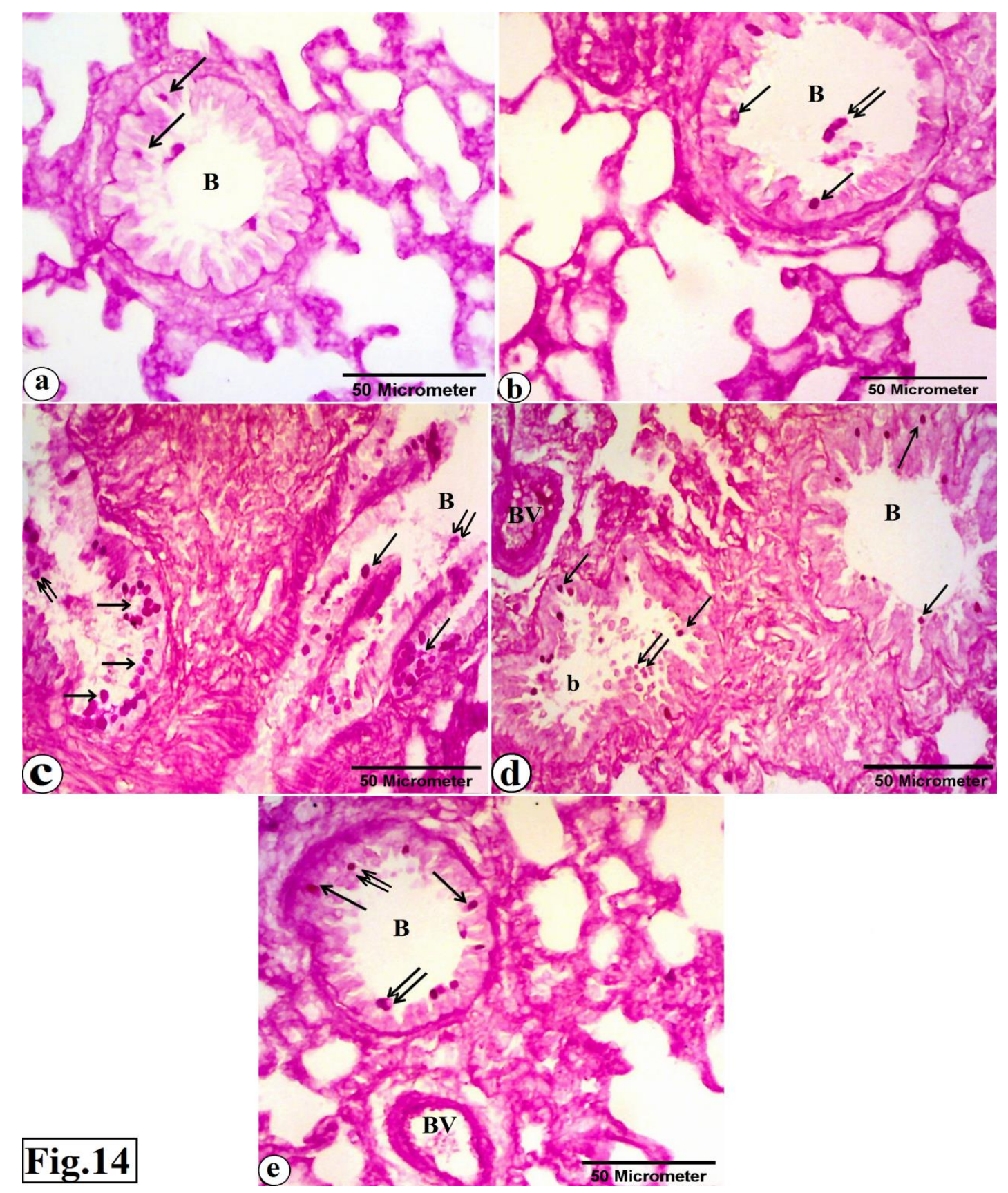

Figure (14): Photomicrographs of the rat lung from all experimental groups: Control group (a) showing: a few pink-magenta stained PAS-positive cells (single arrows) in the large sized bronchioles (B). Combined Aloe vera + Ag NPs group (b) showing: similar results to the control. Few inflammatory cells (double arrows) in the bronchiolar lumen (B) are also noticed. Ag-Nps group (c) and the recovery group (d) showing: strong PAS -positive reaction in the numerous mucus secreting cells (single arrows) lining the large bronchioles (B). Inflammatory cells (double arrows) in the bronchiolar lumen are also observed. There is an intense PAS reaction in the pulmonary blood vessels (BV). Aleo vera-treated group (e) showing: a marked reduction of PAS-positive reaction (single arrows) within the bronchiolar epithelial lining (B). PAS positive reaction in the pulmonary blood vessels 
(BV) and few inflammatory cells (double arrows) in the bronchiolar lumen are also noticed (Periodic acid Schiff reaction a-e $x$ 400, Scale bar $=50 \mu \mathrm{m}$ ).

\section{Immunohistochemical results:}

a. Inducible nitric oxide synthase (iNOS) immunohistochemical reaction

There was an undetectable expression of iNOS immunohistochemistry within the alveolar region as well as within the cells of the lung interstitium in the control (GI) and in the combined aloe vera gel + AgNPs (III) groups. However, a weak positive brown immunoreaction could be detected inside the cytoplasm of few bronchiolar epithelial cells (Figures 15a, 15b).

Conversely, in the Ag-NPs injected (GII) and in the recovery (GIV) groups, strong positive dark brown iNOS immunoreaction was markedly detected within the cytoplasm of the bronchiolar epithelial lining (Figures 15c, 15e) and within the numerous alveolar epithelial cells as well as those of interalveolar septa and the interstitial cells (Figures 15d, 15f) confirming apoptotic changes in lung tissue compared with the control group.

A noticeable reduction in the expression of iNOS was detected in the aloe vera-treated group (V) which revealed minimal positive brown cytoplasmic immunoreaction for iNOS in the bronchiolar epithelial lining (Figure 15g), within few alveolar epithelial cells and within few pulmonary interstitial cells (Figure 15h) compared with the Ag-NPs injected group. 


\section{Mona Mohamed Abd El-Galil and Ahmad Mohammad Farag Alkot}

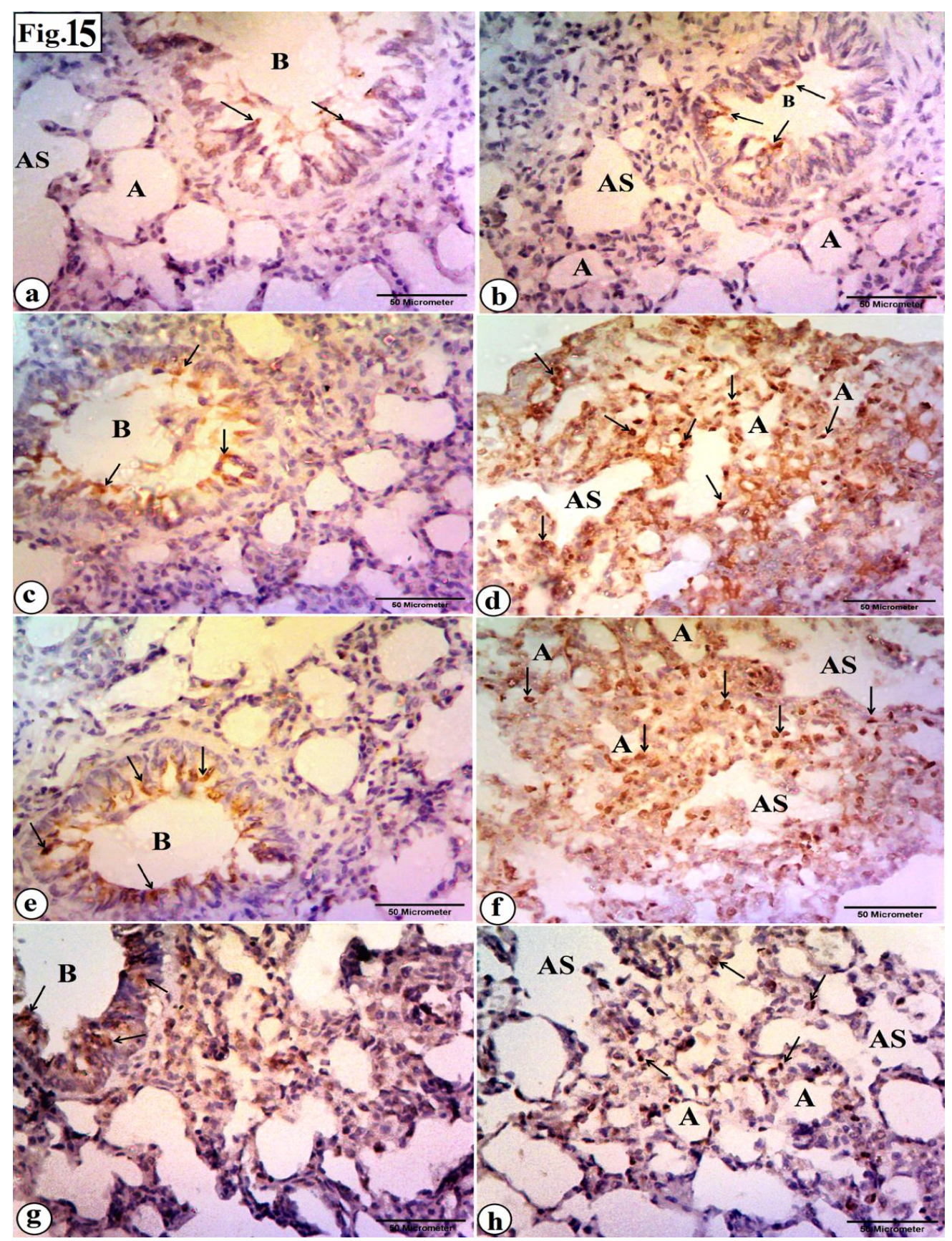

Figure (15): Photomicrographs of the iNOS immunohistochemistry in the rat lung from all experimental groups: Control group (a) showing: undetectable iNOS expression in the alveolar epithelial cells (A) and air sacs (AS). A weak positive cytoplasmic immunoreaction for iNOS (arrows) is observed in a few bronchiolar (B) epithelial lining. Combined Aloe vera + Ag NPs group (b) showing: similar results as in the control. AgNps group (c, d) and the recovery group (e, f) showing: strong positive iNOS immunoreaction (arrows) in many alveolar epithelial cells (A), air sacs (AS), and those of interalveolar septa and in the cytoplasm of the bronchiolar (B) epithelial lining. Aleo veratreated group $(\mathrm{g}, \mathrm{h})$ showing: minimal positive cytoplasmic immunoreaction for iNOS (arrows) in the bronchiolar epithelial lining (B) and in a few alveolar epithelial cells and in a few cells of the lung interstitium (iNOS immunohistochemical staining a-h x400, Scale bar $=\mathbf{5 0 \mu m ) . ~}$ 
b. Alveolar macrophage CD-68 immunohistochemical reaction

Immunohistochemical-stained sections of CD-68 showed few cells with weak positive cytoplasmic immunoreaction in the alveolar macrophages within the interalveolar septa in the control group (I) (Figure 16a). The combined aloe vera gel + Ag-NPs group (III) showed some increase in the positive cytoplasmic immunoreaction for CD-68 in some alveolar cells and in cells of the interalveolar septa compared to the control (Figure 16b).

Immunohistochemical-stained sections of CD-68 in the Ag-NPs injected (Figure 16c) and in the recovery (Figure 16d) groups showed numerous cells with strong positive cytoplasmic immunoreaction in the interalveolar septa between alveolar cells and in the alveolar lumen compared with the control group.

A noticeable decrease in the positively stained CD-68 immunoreaction was observed in the aloe vera-treated group (V) which evident as mild positive cytoplasmic immunoreaction in some alveolar cells and in cells of inter alveolar septa compared with the Ag-NPs injected group (Figure 16e). 


\section{Mona Mohamed Abd El-Galil and Ahmad Mohammad Farag Alkot}

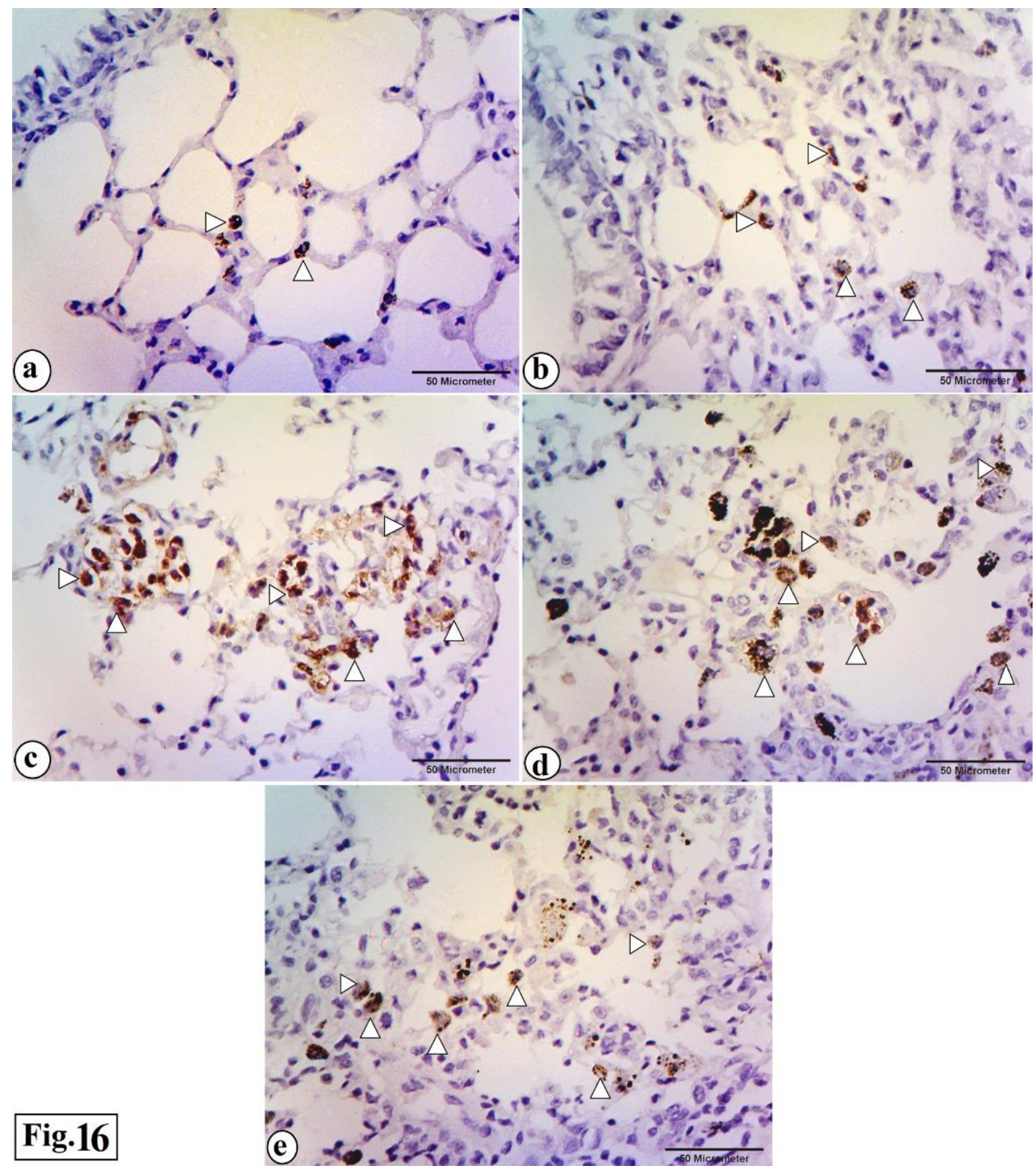

Figure (16): Photomicrographs of the CD 68 immunostained sections in the lung tissue from all experimental groups: Control group (a) showing: weak positive cytoplasmic immunoreaction for CD68 (arrow heads) in a few cells of the interalveolar septa. Combined Aloe vera + Ag NPs group (b) showing: some increase in the positive cytoplasmic immunoreactions in some alveolar cells and in cells of the interalveolar septa compared to the control. Ag-Nps group (c) and the recovery group (d) showing: strong positive CD 68 cytoplasmic immunoreaction (arrow heads) in a numerous cells within the interalveolar septa and in the lumen of the damaged alveoli. Aleo vera-treated group (e) showing: mild positive cytoplasmic immunoreaction for CD 68 (arrow heads) in some alveolar cells and in cells of interalveolar septa (CD68 immunohistochemical staining ae $\mathbf{4 0 0}$, Scale bar $=50 \mu \mathrm{m}$ ). 


\section{Histo-morphometric results:}

Table (3) revealed a significant increase in the mean thickness of the interalveolar septa in AgNPs- injected group (II) and in the recovery group (IV), as compared to the control rats in $\mathrm{H} \& \mathrm{E}$ stained sections $(\mathrm{P}<0.001$ versus the control group).

Interestingly, there was a statistically significant increase in the mean area percentage of the collagen fibers at the pulmonary interstitial tissue and around the congested pulmonary blood vessels in the Mallory trichrome stained sections as well as a significant elevation in the percentage of PAS-positive mucus which was secreted by mucous secreting epithelial cells lined some large-sized bronchioles in both GII and GIV that recorded the highest mean values when compared to the control rats $(\mathrm{P}<0.001)$.

As regarding the immunohistochemical results, there was a significant increase in the mean area percentage of the iNOs and in the mean number of CD-68 positive immunostained cells in the AgNPsinjected (II) and in the recovery (IV) groups, when compared to the control rats $(\mathrm{P}<0.001)$.
Inversely, administration of crude aloe vera gel extract ameliorated the destructive effect of Ag NPs on the lung tissue in the combined aloe vera gel $+\mathrm{Ag}-$ NPs group (III) and in the aloe veratreated group (V) as demonstrated by a significant decrease in the thickness of the interalveolar septum coupled with a significant decrease in the area percentages of collagen fibers at the pulmonary interstitial tissue, and a significant decrease in the percentage of PAS-positive mucus-secreting epithelial cells lined some large-sized bronchioles in comparison with the AgNPs- injected and the recovery groups $(\mathrm{P}<0.001)$.

Also, the aloe vera administered groups (III and V) displayed a statistically significant decrease in the mean area $\%$ of iNOs as well as in the mean number of CD-68 alveolar macrophages as compared to the AgNPs-injected and the recovery groups respectively $(\mathrm{P}<0.001)$.

Interestingly, improvement was more pronounced in the combined aloe vera gel + Ag-NPs group (III) than in the aloe vera-treated group $(\mathrm{V})$. The latter $(\mathrm{GV})$ could not reach the normal values with a significant difference in comparison to the control group $(\mathrm{P}<0.001)$ (Table 3). 


\section{Mona Mohamed Abd El-Galil and Ahmad Mohammad Farag Alkot}

Table (3): One-way ANOVA followed by post hoc Tukey's comparative statistical analysis of the mean thickness of the interalveolar septa, area percentage (\%) of collagen at interstitial tissues, percentage of PAS-positive epithelial cells/ bronchiole, the area percentage of positive iNOS immunoreactivity, and the number of CD-68 positive alveolar macrophages/ HPF in the different studied groups.

\begin{tabular}{|c|c|c|c|c|c|c|}
\hline Studied groups & $\begin{array}{c}\text { Control } \\
(n=6)\end{array}$ & $\begin{array}{c}\text { Ag NPs- } \\
\text { injected } \\
(\mathrm{n}=6)\end{array}$ & $\begin{array}{c}\text { Aloe vera gel } \\
+ \text { Ag NPs } \\
(n=6) \\
\end{array}$ & $\begin{array}{l}\text { Recovery } \\
\text { group } \\
(\mathbf{n}=6)\end{array}$ & $\begin{array}{c}\text { Aloe vera gel } \\
\text { treated } \\
(\mathrm{n}=6)\end{array}$ & $P$ \\
\hline $\begin{array}{c}\text { Thickness of } \\
\text { IAS }(\mu \mathrm{m})\end{array}$ & $0.74 \pm 0.1$ & $17.3 \pm 2.3^{\mathrm{a}^{*}}$ & $0.96 \pm 0.2^{b^{*} c^{*}}$ & $16.9 \pm 3.1^{\mathrm{a}^{*}}$ & $2.91 \pm 0.71^{\mathrm{a}^{*} \mathrm{~b}^{*} \mathrm{c}^{*}}$ & $<0.001$ \\
\hline $\begin{array}{c}\text { Area \% of } \\
\text { interstitial collagen } \\
\text { fibers }\end{array}$ & $1.9 \pm 0.5$ & $22.6 \pm 4.9^{\mathrm{a}^{*}}$ & $2.3 \pm 0.6^{b^{*} c^{*}}$ & $19.8 \pm 1.9^{a^{*}}$ & $7.74 \pm 0.9^{a^{*} b^{*} c^{*}}$ & $<0.001$ \\
\hline $\begin{array}{l}\% \text { of PAS+ ve } \\
\text { epithelial cells/ } \\
\text { bronchiole }\end{array}$ & $1.03 \pm 0.21$ & $22.6 \pm 5.2^{\mathrm{a}^{*}}$ & $2.0 \pm 0.41^{\mathrm{a} * \mathrm{~b}^{*} \mathrm{c}^{*}}$ & $19.3 \pm 6.5^{\mathrm{a}^{*}}$ & $2.9 \pm 0.6^{\mathrm{a}^{*} \mathrm{~b}^{*} \mathrm{c}^{*}}$ & $<0.001$ \\
\hline $\begin{array}{c}\text { Area \% } \\
\text { of iNOS } \\
\text { immunopositivity } \\
\text { /HPF } \\
\end{array}$ & $0.02 \pm 0.01$ & $34.3 \pm 6.5^{\mathrm{a}^{*}}$ & $0.07 \pm 0.022^{a * b *} c^{*}$ & $30.02 \pm 6.1^{a^{*}}$ & $3.9 \pm 0.8^{a^{*} b^{*} c^{*}}$ & $<0.001$ \\
\hline $\begin{array}{c}\text { Mean number } \\
\text { of CD68 alveolar } \\
\text { macrophages } \\
\text { /HPF }\end{array}$ & $2.5 \pm 0.6$ & $24.9 \pm 8.3^{\mathrm{a}^{*}}$ & $4.8 \pm 0.8^{\mathrm{a}^{*} \mathrm{~b}^{*} \mathrm{c}^{*}}$ & $22.7 \pm 7.2^{\mathrm{a}^{*}}$ & $9.34 \pm 1.9^{a^{*} b^{*} c^{*}}$ & $<0.001$ \\
\hline
\end{tabular}

All results were expressed as mean \pm SD; SD: standard deviation; n: number of rats; Ag-NPs: Silver nanoparticles; IAS: interalveolar septum; HPF: high power field.

${ }^{a}$ significant versus control group

${ }^{\mathrm{b}}$ significant versus AgNPs-injected group

${ }^{\mathrm{c}}$ significant versus recovery group

There was a significant positive correlation between MDA \& iNOS and between MDA \& the number of alveolar macrophages with a correlation factor $(\mathrm{R})$ 0.983 and 0.949 respectively (Figure 17). 


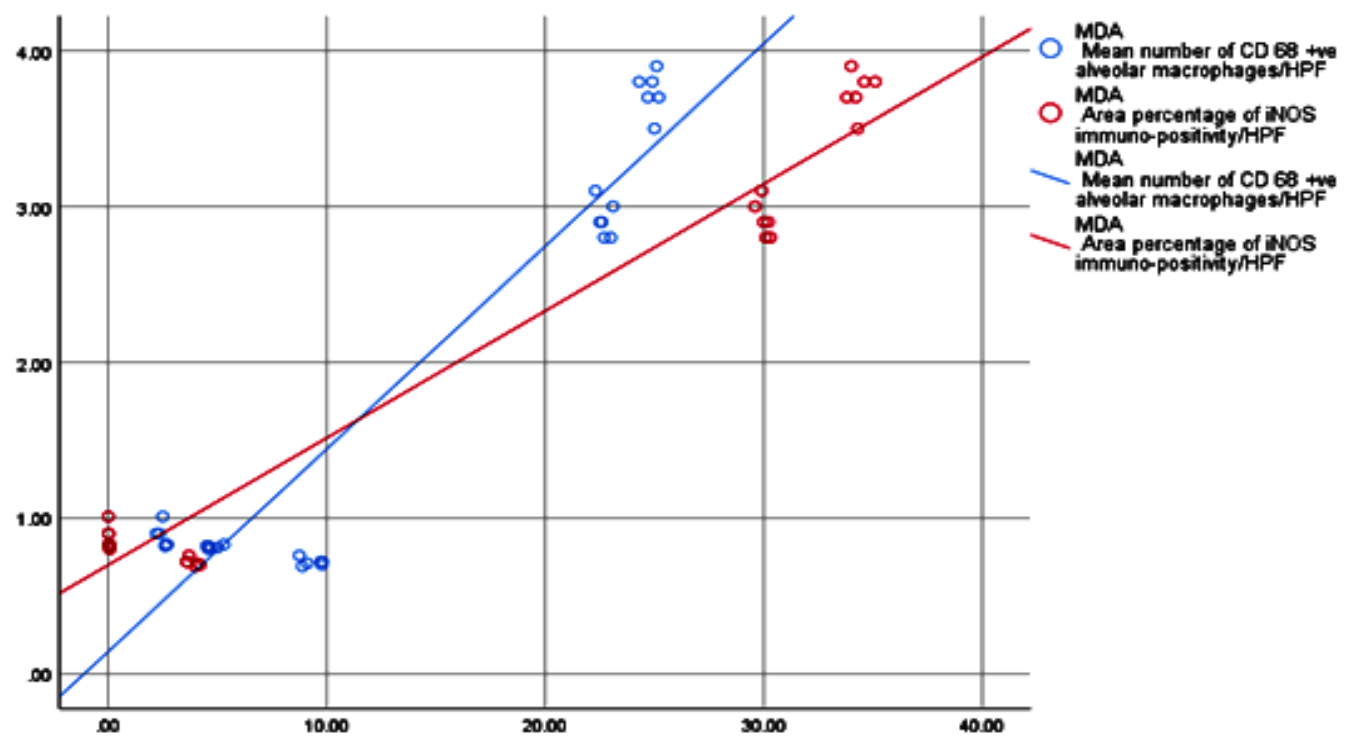

Figure (17): The correlation between MDA \& iNOS and between MDA \& number of alveolar macrophages

There was a significant positive correlation between TNF- $\alpha$ \& iNOS and between TNF- $\alpha$ \& the number of alveolar macrophages with a correlation factor $(\mathrm{R})$ 0.980 and 0.975 respectively (Figure 18).
Also, there was a significant positive correlation between IL-6 \& iNOS and between IL-6 \& the number of alveolar macrophages with a correlation factor $(\mathrm{R})$ 0.971 and 0.987 respectively (Figure 19).

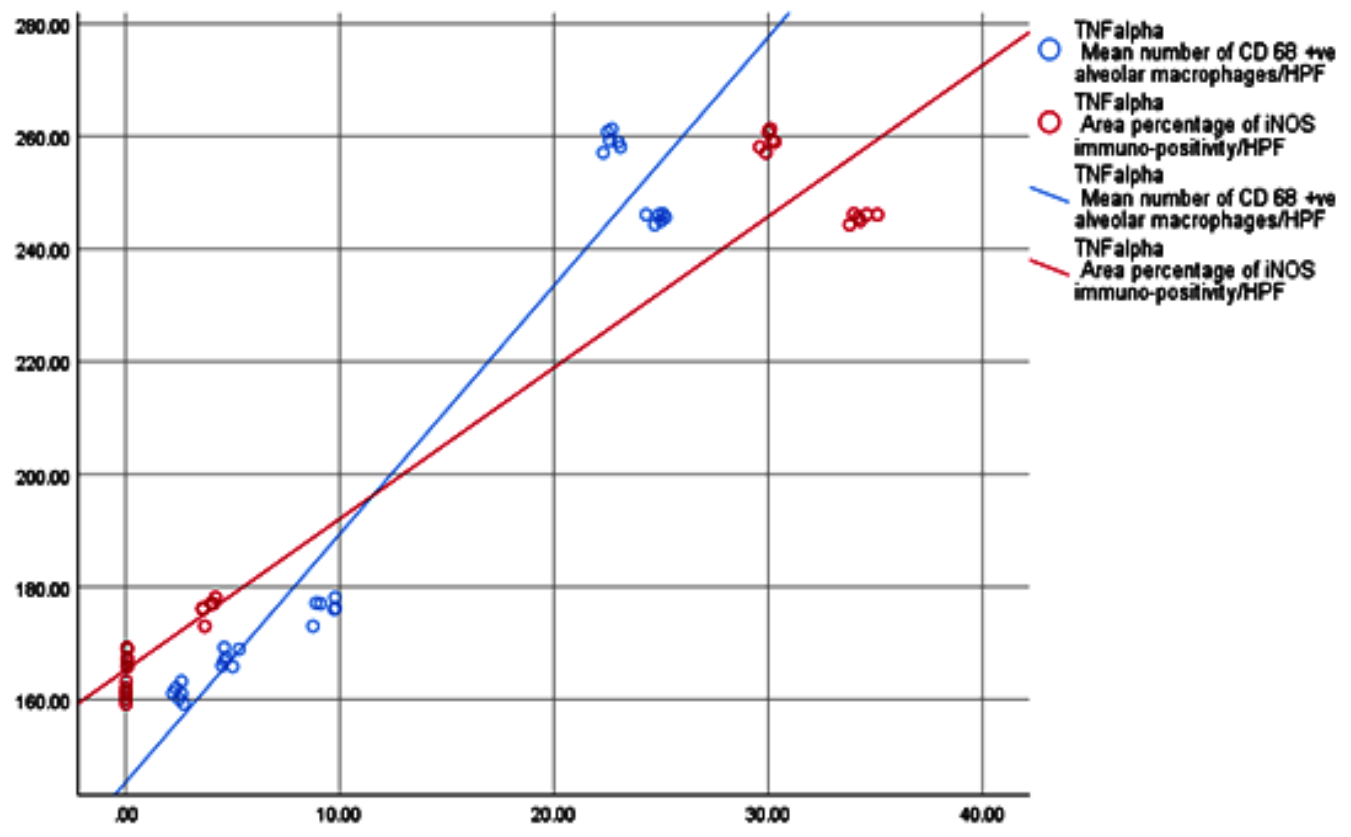

Figure (18): The correlation between TNF- $\alpha$ \& iNOS and between TNF- $\alpha$ \& number of alveolar macrophages 


\section{Mona Mohamed Abd El-Galil and Ahmad Mohammad Farag Alkot}

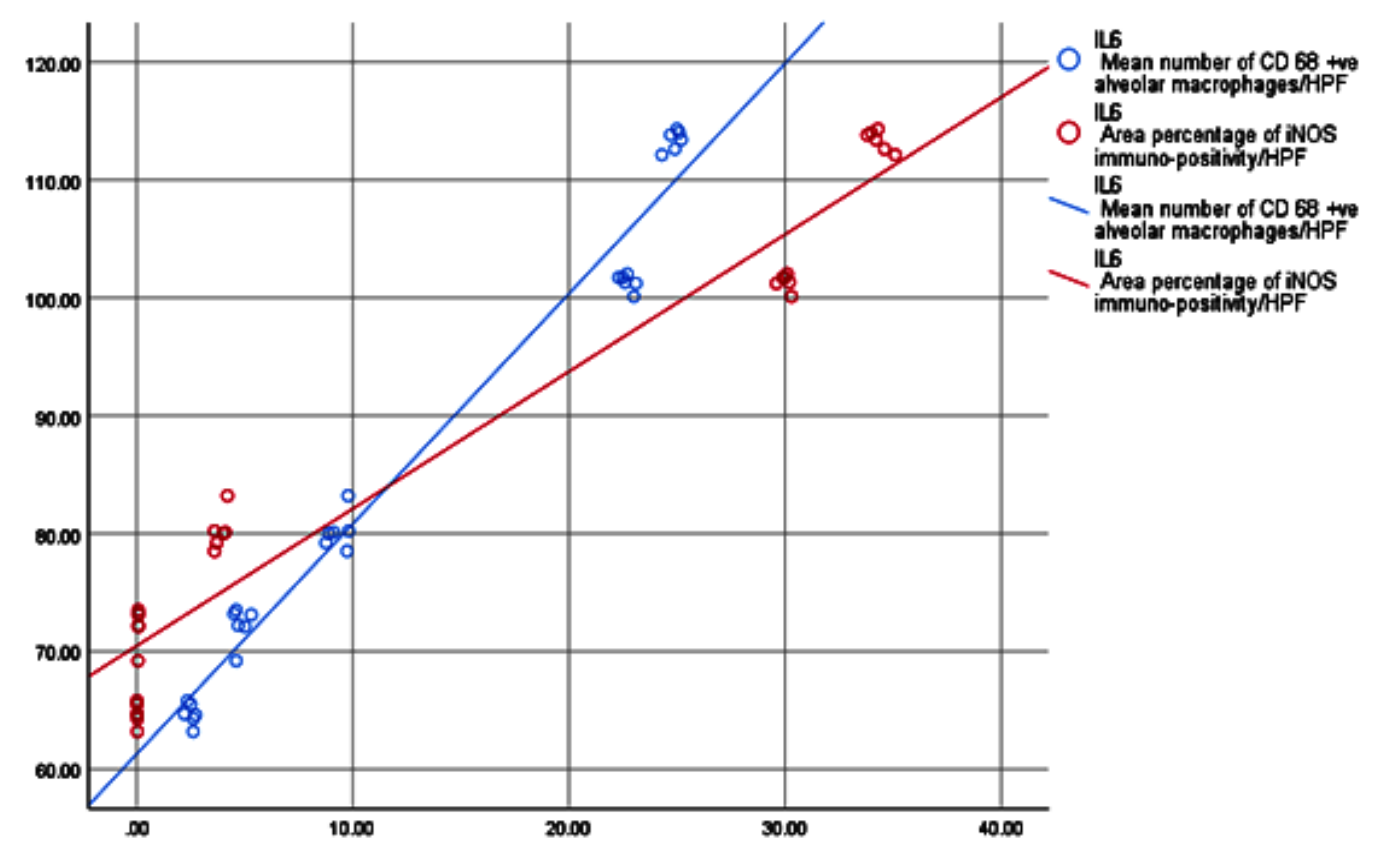

Figure (19): The correlation between IL-6 \& iNOS and between IL-6 \& the number of alveolar macrophages

The closer the correlation factor to \pm 1 the stronger the correlation. This is indicating that the recruitment of alveolar

\section{DISCUSSION}

Silver nanoparticles (Ag-NPs) are amongst the most broadly connected nanomaterial in the biomedical and pharmacological fields due to their antimicro $\neg$ bial and antifungal properties, and their potential for application in the treatment of diseases that need a constant drug concentration in the blood or targeting of a specific tissue (Tavares et al., 2012). Also, Ag-NPs have common manufacturing applications in cosmetics, water filters, air conditioning filters, and food industries (Ganapathi et al., 2017).

Unfortunately, possible undesirable effects and harmful interactions with biological systems and the environment may occur related to discharging organically dynamic $\mathrm{Ag}+$ into the human macrophages and the increased expression of iNOS are strongly related to oxidative stress.

body which can be accumulated in various organs, whereby generating various inflammatory responses with the potential to generate cytotoxicity (Ganapathi et al., 2017 and Al-Bishri, 2018). Studies of Valerio-García et al. (2017) and Zhang et al. (2018) stated the correlation between Ag-NPs and the oxidative stress induction with subsequent inflammation and tissue damage.

More attention has been paid to the protective effects of natural antioxidants against drug-induced toxicity. Aloe vera is a potential source of natural antioxidative phenolic compounds, which can restore the oxidant/antioxidant balance, prevent or attenuate oxidant insults and can replace the synthetic antioxidant in the field of cosmetics, pharmaceuticals, and 
foods (Bendjedid et al., 2021). Accordingly, the present study was designed to clarify the effects of orally consumed crude aloe vera on Ag-NPsinduced lung cytotoxicity in the adult male rat model.

Male adults' albino rats were chosen in the present work, to exclude the antioxidant effect of natural estrogen (Tatler et al., 2016) and to avoid the effect of certain X-linked genes (Paixão et al., 2017).

In the present study, Ag-NPs showed a significant increase in the serum cytokines; tumor necrosis factor-alpha (TNF- $\alpha$ ), interleukin 6 (IL-6) and the oxidative stress markers; malondialdehyde (MDA), coupled with a significant decrease in the total antioxidant capacity (TAC) that was reported in the Ag NPsinjected and the recovery groups (II, IV) in comparison with the control group (I).

The current study revealed a significant positive correlation between the proinflammatory markers; TNF- $\alpha$ and IL-6 and a significant negative correlation between TAC and MDA in both Ag-NPs injected and the recovery (II, IV) groups as compared to the control rats.

These biochemical parameters were well correlated with the variable degrees of histopathological alterations and immunohistochemical results which were detected in the lung tissue of the Ag-NPs injected and the recovery groups (II \&IV) where they revealed thickening of the interalveolar septum, distortion and collapsed alveoli, detached cells with shrunken pyknotic nuclei, mononuclear cellular infiltration, thickened vessel wall, areas of haemorrhage and extravasation of RBCs in interstitium in $\mathrm{H} \& \mathrm{E}$ stained sections as well as extensive interstitial fibrosis.

A significant increase in MDA level in the present study was explained by the fact that highly reactive oxygen metabolites, particularly hydroxyl radicals $(\bullet \mathrm{OH})$, react with unsaturated fatty acids of membrane phospholipid components producing MDA, this is considered a harmful lipid peroxidation indicator in the pathological process. Hence, oxidative stress is considered a key mechanism inducing cytotoxicity (Abd El-Maksoud et al., 2019). However, oxidative stress is not the only cause of cellular damage but also the interaction between the nanoparticles and the cellular biomolecules to form nanoparticle-protein complexes with cellular proteins, enzymes and DNA which alter cellular physiological and biological processes with subsequent cellular injury (Al-Bishri, 2018 and Yousef et al., 2019).

Amin et al. (2015); Cui et al. (2018) and Dąrowska-Bouta et al. (2019) attributed the histopathological alterations which was detected in the lung tissue to the systemic and immunotoxic effect of AgNPs via the release of the oxidative stress products as well as alveolar macrophages activation concomitant with the up-regulation of pro-inflammatory and pro-neutrophilic cytokines that increase the membrane permeability to ions such as $\mathrm{Ca}+2$, inactivation of structural proteins, ion pumps, increased lipid peroxidation of the cell membranes and a depletion of glutathione, as well as potentiate elastase secretion from the inflammatory cells as a consequence of decrease the $\alpha$-antitrypsin 1 activity, which in turn breaks down elastin protein lining the air sacs and the 


\section{Mona Mohamed Abd El-Galil and Ahmad Mohammad Farag Alkot}

pulmonary vessels thereby disrupt the alveolar capillary membranes and allow the leakage of proteinaceous fluid into the pulmonary parenchyma causing alveolar epithelial injury with alterations of the alveolar capillary barrier, cytolysis, and increasing oxidative stress load.

Makama et al. (2018); Abd ElMaksoud et al. (2019) and Yousef et al. (2019) stated that Ag-NPs-induced cytotoxicity may be partially caused by the direct action of $\mathrm{Ag}+$ ions being dissolute from Ag-NPs, that are capable of penetrating cell membranes and other biological barriers, subsequently bioaccumulation in the lung tissue, and bind to thiol groups in the cell which is implicated in the structural protein damage by desulphurization and enhance the generation of free radicals, intracellular reactive oxygen species (ROS) and reactive nitrogen species (RNS), that are responsible for inducing oxidative and nitrosative damage which may increase the permeability of the lung epithelium to Ag-NPs and the conceivable mechanisms include actuation of lysosomal acid phosphatase activity, interruption of the actin cytoskeleton, incitement of phagocytosis, hindrance of Na-K-ATPase, eliciting oxidative DNA damage, prompting cellular necrosis and apoptosis and hence elevating the levels of the proinflammatory cytokines including TNF- $\alpha$ and IL- 6 .

Syafiuddin et al. (2017) and Al-Bishri (2018) stated that Ag-NPs can also passively penetrate into cell organelles, especially mitochondria, drastically impaired mitochondrial $\beta$-oxidation via changing the mitochondrial inner membrane composition, translocation of intra-mitochondrial protein (apoptosisinducing factor), disruption of the membrane potential, decrease bioenergetics, adenosine triphosphate (ATP) and creatine kinase levels suggest a potential for metabolic and cell cycle arrest which underpins cytotoxicity ending with progressive cell damage.

Gamad et al. (2018) attributed the alveolar collapse to the degeneration of type II pneumocytes which affect surfactant secretion with an increase in surface tension that impairs the blood flow leading to alveolar collapse and chronic obstructive pulmonary disease (COPD).

Cellular infiltrations and extravasation were reported by Alarifi et al. (2013) and Setyawati et al. (2013) who stated that nanoparticles may disturb the vascular endothelium cadherin (VE-cadherin) due to the direct combination of nanomaterials to VE-cadherin which affects permeability of the cell membranes and the endothelial cell-cell integrity and would attract immune cells in the peripheral tissue, causing inflammatory reactions.

In agreement with Arpag et al. (2018), the infiltration of inflammatory cells and the predominance of type II pneumocytes together with increased deposition of extracellular matrix proteins and endothelial hyper proliferation that may be linked to the ROS accumulation in lung resulted in remarkable thickening of the interalveolar septa which was histomorphometrically confirmed.

Interstitial fibrosis was consistent with the studies of Asghari et al. (2015); Zhu et al. (2016) and Gamad et al. (2018) who stated that pulmonary fibrosis is simply the consequence of inflammation that 
associated with increased levels of proinflammatory cytokines, C-reactive protein, tissue plasminogen activator ( $\mathrm{t}-$ PA), and nuclear transcription factorKappa-B (NF-kB) that directly upregulate profibrotic transforming growth factorbeta 1 genes (TGF- $\beta 1$ ) in the lung which induces elevation of hydroxyproline content, fibronectin production and type I collagen by the activated fibroblasts, and promotes epithelial mesenchymal transformations into myofibroblasts, as well as inhibition of proteases that degrade the extracellular matrix contribute greatly to severe pulmonary fibrosis which was morphometrically confirmed by a significant increase in the area percentage of collagen within the lung interstitium in the Mallory trichrome stained sections of Ag-NPs group.

A significant increase in the percentage of PAS-positive epithelial cells in largesized bronchiole in the Ag-NPs groups that was reported in the current study were explained on the basis of ROS and oxidative stress. Oxidative stress-mediated epidermal growth factor receptor (EGFR) activation in the airway epithelium is the key pathway that leads to airway mucus hypersecretion, via chemically modifying the receptor, altering its structure, and enhancing its kinase activity (Paulsen et al., 2011). In addition, activation of EGFR can over express of goblet cell Bcl-2 (antiapoptotic protein) gene (Kim et al., 2011) as well as down-regulate a transcriptional repressor of mucin genes named Forkhead Box A2 (FOXA2) (Hao, et al., 2014).

In addition, a number of studies have shown that cytokines specifically, $\mathrm{T}$ helper 2 (Th2)-type cytokines such as IL4, IL-9, and IL-13 may induce mucin-2
(MUC2) mRNA overexpression and increase mucus glycoconjugate production which play an important role in mediating overproduction and hypersecretion of mucus in inflammatory lung disease (Harris, et al., 2005 and Asghari et al., 2015). Importantly, these mechanisms resulting in goblet cell hyperplasia in the airway epithelium with excess mucus production which overwhelms the mucociliary clearance, resulting in defective mucosal defense and contributing to cell death and lung disease (Hao, et al., 2014).

A significant increase in the mean number of CD-68 positive immunoreactive cells that was evident in the lung sections of the Ag-Nps injected group could be explained as a compensatory mechanism to maintain normal lung function against the hazards of the inflammatory cascade which affects oxidative metabolism of alveolar macrophages and undergoes activation, as aside from responding to foreign nanoparticles (Nps) stimuli (Anderson et al., 2015 and Ahmed et al., 2017).

Furthermore, pro inflammatory cytokines, induce the expression of iNOS ,catalyze the decomposition of arginine and consequently the generation of large quantities of nitric oxide (NO).Simultaneously, excess NO binds to $\mathrm{O} 2$ to form a strong oxidant (ONOO) that affects pulmonary vascular permeability and the diffusion function of lung tissue, destroys the cytomembrane and DNA ( $L i$ et al., 2015 and Ahmed, 2017), mediates mitochondrial dysfunction (Albert et al., 2017) and can inhibit sirtuin 1 (SIRT1) thereby inhibiting P53 pathway dependent apoptosis through a deacetylation pathway 


\section{Mona Mohamed Abd El-Galil and Ahmad Mohammad Farag Alkot}

and ultimately promoting apoptosis and necrosis (Liu et al., 2019). This was morphometrically confirmed by a significant increase in the area percentage of pulmonary iNOS levels within the lung interstitium of Ag-NPs group.

The mean area percentage was chosen instead of the mean optical density of brown stained iNOS because the main objective is to quantify the cellular localization and expression of iNOS which was expressed in both cytoplasm and nucleus of all affected cells by the same manner with no need to localize iNOS in different compartments of the cell separately (Gibson-Corley et al., 2013).

The closer the correlation factor $(\mathrm{R})$ to \pm 1 the stronger the correlation (Akoglu, 2018). The strong correlations between oxidative stress bio marker MDA, the levels of proinflamatory cytokines TNF- $\alpha$ \& IL-6 and the pulmonary tissue changes -indicated by increased expression of iNOS and recruitment of alveolar macrophages-clearly showed how Ag-NPs induce a cascade reaction at humoral, cellular and molecular levels that ended in marked tissue damage, system affection and significant correlated reduction in body weight (Shi et al., 2014 and FloresLópez et al., 2019).

In the present study, Ag-NPs showed a significant decrease in the final body weight in the Ag NPs- injected and in the recovery groups (II, IV) as compared with the control group (I). This was in agreement with Yin et al. (2015) and Arisha et al. (2019) who stated that bodyweight is a sensitive indicator of toxic chemical effects. They explained the reduction in body weight by the fact that nanomaterial belongs to the size range of common proteins, virus and some common immunogens, and may cause various immunotoxic responses and inflammation with increased oxidative stress and subsequent tissue damage.

Han et al. (2018) and Makama et al. (2018) added that inflammatory conditions with elevated levels of IL-6 and TNF- $\alpha$ are well known to be associated with weight loss as these proinflammatory cytokines induce fat wasting, muscle atrophy, and reduces appetite. Similar phenomena were also reported in nickel and gold nanoparticles (Arisha et al., 2019). On the contrary, the study of El Mahdy et al. (2015) reported no significant change in body weights in the Ag-NPs-treated rats when compared with control rats. This may be attributed to the type of animal used, dose, and duration of the study where they injected female rats with doses of Ag-NPs lower than the dose used in the current study.

The recovery group (IV) in the present study, did not restore the histological findings compared to the control group that was confirmed by the insignificant difference between the recovery and the Ag-NPs groups in all biochemical and histomorphometric results.

In the current study, crude Aloe vera gel was given by orogastric tube ensured that the accurately calculated dose of the aloe vera gel which putative health benefits in reducing experimental malignancies and experimental infections occur when taken orally (Im et al., 2010).

Administration of crude aloe vera extracts either concomitantly with AgNPs 
(GIII) or as a therapeutic agent after induction of lung cytotoxicity $(\mathrm{GV})$ in the present study, revealed great improvement in the biochemical indices that was affirmed by a significant reduction in the TNF- $\alpha$, IL-6 and MDA levels coincided with a significant elevation in the TAC levels and successfully ameliorated the vigorous AgNPs-induced lung injury evidenced by partial restoration in the histological structure of the lung parenchyma, recruitment of inflammatory cell infiltrations, improve the functional integrity of endothelial cells of the blood vessels which in turn subsided congestion and extravasation of RBCs and reduced the procollagen type I, III deposition in the lung interstitium that was confirmed by, a significant decreased thickness of the interalveolar septa, collagen fiber deposition at the lung interstitium, mucussecreting goblet cells in large-sized bronchiole, CD-68 alveolar macrophage number and the area percentage of iNOS expressionas compared to Ag-NPs group, indicating marked improvement in oxidative stress induced by Ag-NPs with strong anti-inflammatory and antioxidant properties (Maan et al., 2018 and Sánchez et al., 2020).

This improvement was more pronounced in the combined aloe vera+Ag-NPs group (III) than in $\mathrm{GV}$ as evident by observation of congested vessels with few inflammatory cell infiltrations and few extravasated RBCs in the lung interstitium of the Aloe vera treated group $(\mathrm{V})$, indicating the powerful protective effect of Aloe Vera against lung complications of silver nanoparticles.

The antioxidant, anti-inflammatory, and anti-apoptotic effects of Aloe vera could be related to its high contents of $\alpha$ tocopherol (vitamin E),ascorbic acid (vitamin $\mathrm{C}$ ), vitamin $\mathrm{A}$, and vitaminB12, carotenoids, tannins, flavonoids, carbohydrates, minerals like zinc and selenium and a fantastic amalgam of phenolic compounds such as anthraquinones, emodin, chromones, chatechin hydrate, caffeic acid, and quercetin which act as powerful free superoxide radical scavengers due to their redox properties with strengthening the endogenous antioxidant defense system, enhancing the synthesis of endogenous antioxidant enzymes, such as glutathione peroxidase, reductase, catalase and superoxide dismutase, and decreasing the oxidant biomarkers that abets to protect against pro-oxidant-induced membrane and cellular damage (Rahoui et al., 2018; Sumi et al., 2019 and Klaikeaw et al., 2020). Zinc traces present in Aloe vera could be considered as a selective inhibitor of apoptosis as it can inhibit some biological mechanisms in epithelial cell (Sánchez et al., 2020 and Govindarajan and Noor, 2021).

Previous studies of Singh et al. (2018); Fehrmann-Cartes et al. (2019) and Sánchez et al. (2020) have shown that aloeresin, emodin, anthrones, and chromones derivatives of the phenolic compounds of Aloe Vera have a strong anti-inflammatory effect which may be due to the inhibition of the arachidonic acid pathway via acting on both the cyclooxygenase and lipoxygenase pathways, thereby decreasing the production of prostaglandin E2 and proinflammatory cytokines, inhibiting of inducible nitric oxide synthase that can confer protection on inflammatory/immune cells, disrupt 


\section{Mona Mohamed Abd El-Galil and Ahmad Mohammad Farag Alkot}

intrinsic and extrinsic cell death pathways and inhibit pneumocytes type II cell dysplasia by suppressing the secretion of TGF- $\beta 1$ and influencing downstream transcription factors of TGF- $\beta 1$ like down regulation of Smad3 and up regulation of Smad7 genes thereby inhibiting pulmonary interstitial fibrosis.

The polysaccharides present in the gel have immune-potentiating effects and the lectin-like proteins have antiinflammatory effects (Rahman et al., 2017 and Singh et al., 2018). Sánchez et al. (2020) added that C-glucosylchromone in Aloe vera gel, contains the peptidase bradykinase which breaks down the bradykinin and reduces the inflammation so protecting cells from apoptosis induced by oxidative stress in the Ag NPs rats.

\section{CONCLUSION}

The current study showed how Ag-Nps can induce humoral and cellular pathogenic processes and markedly alter the biochemical and histological structure of lung tissue that eventually precipitate a health problem. Therefore, manufacturers should be aware that there may be additional safety considerations for cosmetics and industrial Ag-Nps containing products to decrease exposure to it. Furthermore, Aloe vera could efficiently alleviate the AgNPs-induced lung cytotoxicity in rat model correlated with biochemical, histological, and morphometric results that may be ascribed to the direct antioxidant, free radical scavenging activities, anti-inflammatory properties, anti-apoptotic activities, and powerful flavonoid content.

\section{Funding:}

This research work did not receive any fund or specific grant from funding agencies in the public, commercial, or notfor-profit sectors.

\section{Conflict of interest:}

There is no conflict of interest.

\section{REFERENCES}

1. Abdel-DayemMM, Hatem $M$ and Elgendy MS. (2014): Histological and Immunohistochemical Study on Nitric Oxide Synthase and Effects of Angiotensin Receptor Blockade in Early Phase of Diabetes in Rat Kidney. British Journal of Medicine and Medical Research, 4(17): 3317-3338.

2. Abd El-Maksoud EM, Lebda MA, Hashem AE, Taha NM and Kamel MA. (2019): Ginkgo biloba mitigates silver nanoparticlesinduced hepatotoxicity in Wistar rats via improvement of mitochondrial biogenesis and antioxidant status. Environmental Science and Pollution Research, 26(25): 25844-25854.

3. Ahmed AM. (2017): Inhibition of inducible nitric oxide synthase (iNOS) by simvastatin attenuates cardiac hypertrophy in rats. Folia Morphol (Warsz), 76(1): 1527.

4. Ahmed SM, Abdelrahman SA and Shalaby SM. (2017): Evaluating the effect of silver nanoparticles on testes of adult albino rats (histological, immunohisto-chemical and biochemical study). Journal of Molecular Histology, 48(1): 9-27.

5. Akaberi M, Sobhani Z, Javadi B, Sahebkar $A$ and Emami SA. (2016): Therapeutic effects of Aloe spp. in traditional and modern medicine: a review. Biomed. Pharmacother., 84: 759-772.

6. Akoglu, H. (2018): User's guide to correlation coefficients. Turkish Journal of Emergency Medicine, 18(3): 91-93.

7. Akpan UP, Nna VU, Ikpi DE, Osim EE and Antai AB. (2014): Effect of Crude Aloe vera Gel on Serum Enzymes, Proteins and Liver Histology in Alloxan - Induced Diabetic 
Rats. International Journal of Science and Research (IJSR), 3(6): 114-119.

8. Alarifi S, Ali D, Al-Doaiss AA, Ali BA, Ahmed $M$ and Al-Khedhairy AA. (2013): Histologic and apoptotic changes induced by titanium dioxide nanoparticles in the livers of rats. International Journal of Nanomedicine, 8: 3937-3943.

9. Albert M, Corsilli D, Williamson DR, Brosseau M, Bellemare P, Delisle S, Nguyen AQ and Varin F. (2017): Comparison of inhaled milri $\neg$ none, nitric oxide and prostacyclin in acute respiratory distress syndrome. World J Crit Care Med., 6(1): 74 78 .

10. Al-Bishri WM. (2018): Toxicity study of gold and silver nanoparticles on experimental animals. Pharmacophore, 9(1): 48-55.

11. Amin YM, Hawas AM, El-Batal AI, Hassan SM and Elsayed ME. (2015): Evaluation of Acute and Subchronic Toxicity of Silver Nanoparticles in Normal and Irradiated Animals. British Journal of Pharmacology and Toxicology, 6(2): 22-38.

12. Anderson DS, Silva RM, Lee D, Edwards PC, Sharmah A, Guo T and Winkle LSV. (2015): Persistence of silver nanoparticles in the rat lung: Influence of dose, size, and chemical composition. Nanotoxicology, 9(5): 591-602.

13. Arisha AH, Ahmed MM, Kamel MA, Attia YA and Hussein MMA. (2019): Morin ameliorates the testicular apoptosis, oxidative stress, and impact on blood-testis barrier induced by photo-extracellularly synthesized silver nanoparticles. Environmental Science and Pollution Research, 26(28): 28749-28762.

14. Arpag H, Gül M, Aydemir Y, Atilla N, Yiğitcan B, Cakir T, Polat C, Pehirli Ö and Sayan M. (2018): Protective Effects of Alpha-Lipoic Acid on Methotrexate-Induced Oxidative Lung Injury in Rats. Journal of Investigative Surgery, 31(2): 107-113.

15. Asghari M H, Hobbenaghi R, Nazarizadeh A and Mikaili P. (2015): Hydroalcoholic extract of Raphanus sativus L. var niger attenuates bleomycin induced pulmonary fibrosis via decreasing transforming growth factor $\beta 1$ level. Res Pharm Sci., 10(5): 429435.

16. Bancroft JD and Layton C. (2013): The hematoxylin and eosin, connective mesenchymal tissues with their stains. In: Suvarna SK, Layton C and Bancroft JD editors. Bancroft's Theory and practice of histological techniques.7th edition. Pbl. Churchill Livingstone. Philadelphia. PP: 173212 and 215-238.

17. Baun A, Sayre $P$, Steinhäuser KG and Rose J. (2017): Regulatory relevant and reliable methods and data for determining the environmental fate of manufactured nanomaterials. NanoImpact, 8: 1-10.

18. Belikoff BG, Vaickus LJ, Sitkovsky $M$ and Remick DG. (2012): A2B Adenosine Receptor Expression by Myeloid Cells Is Proinflammatory in Murine Allergic-Airway Inflammation. The Journal of Immunology, 189(7): 3707-3713.

19. Bendjedid S, Lekmine S, Tadjine A, Djelloul $R$ and Bensouici C. (2021): Analysis of phytochemical constituents, antibacterial, antioxidant, photoprotective activities and cytotoxic effect of leaves extracts and fractions of Aloe vera. Biocatalysis and Agricultural Biotechnology, 33: 101991:1165-1173.

20. Bridle H. (2021): Nanotechnology for detection of waterborne pathogens. Water borne Pathogens. 2nd edition. Chapter 9. Pbl. Academic Press. Cambridge. PP: 293-326.

21. Cui $X$, Gong J, Han $H$, He L, Teng $Y$, Tetley T, Sinharay R, Chung KF, Islam T, Gilliland F, Grady S, Garshick E, Li Z and Zhang JJ. (2018): Relationship between free and total malondialdehyde, a well-established marker of oxidative stress, in various types of human biospecimens. Journal of Thoracic Disease, 10(5): 3088-3097.

22. Dąbrowska-Bouta B, Sulkowski G, Strużyński W and Strużyńska L. (2019): Prolonged Exposure to Silver Nanoparticles Results in Oxidative Stress in Cerebral Myelin. Neurotoxicity Research, 35(3): 495504. 


\section{Mona Mohamed Abd El-Galil and Ahmad Mohammad Farag Alkot}

23. Debnath T, Ghosh M, Lee YM, Nath NCD, Lee KG and Lim BO. (2018): Identification of phenolic constituents and antioxidant activity of Aloe barbadensis flower extracts. Food and Agricultural Immunology, 29(1):27-38.

24. Durán N, Durán $M$ and de Souza CE. (2017): Silver and silver chloride nanoparticles and their anti-tick activity: a mini review. Journal of the Brazilian Chemical Society, 28 (6): 927-932.

25. El Mahdy MM, Eldin TAS, Aly HS, Mohammed FF and Shaalan MI. (2015): Evaluation of hepatotoxic and genotoxic potential of silver nanoparticles in albino rats. Experimental and Toxicologic Pathology, 67(1): 21-29.

26. Fehrmann-Cartes $\mathbf{K}$, Coronado $\mathbf{M}$, Hernández AJ, Allende ML and Feijoo CG. (2019): Anti-inflammatory effects of aloe vera on soy meal-induced intestinal inflammation in zebrafish. Fish \& Shellfish Immunology, 95: 564-573.

27. Flores-López LZ, Espinoza-Gómez H and Somanathan R. (2019): Silver nanoparticles: Electron transfer, reactive oxygen species, oxidative stress, beneficial and toxicological effects. Mini review. Journal of Applied Toxicology, 39(1): 16-26.

28. Gamad N, Malik S, Suchal K, Vasisht S, Tomar A, Arava S, Arya DS and Bhatia J. (2018): Metformin alleviates bleomycininduced pulmonary fibrosis in rats: Pharmacological effects and molecular mechanisms. Biomed Pharmacother., 97:1544-1553.

29. Ganapathi AP, Devaki R, Thuniki NR, Manna J, Tirumuru B, Gopu CR and Hasan A. (2017): In vitro assessment of $\mathrm{Ag}$ and $\mathrm{TiO} 2$ nanoparticles cytotoxicity. International Journal of Research in Medical Sciences, 2(4): 1360-1367.

30. Gibson-Corley KN, Olivier AK and Meyerholz DK. (2013): Principles for Valid Histopathologic Scoring in Research Veterinary Pathology, 50(6):1007-1015.
31. Govindarajan $S$ and Noor A. (2021): Carbohydrate fraction of Aloe vera ameliorates inflammation through suppression of pro-inflammatory mediators and oxidative stress in vitro and rats with Freund's adjuvant induced paw edema." Indian Journal of Experimental Biology (IJEB), 59(3): 177-185.

32. Hadrup N, Sharma AK, Loeschner $K$ and Jacobsen NR. (2020): Pulmonary toxicity of silver vapours, nanoparticles and fine dusts: A review. Regulatory Toxicology and Pharmacology, 115: 104690. 1- 9.

33. Han J, Meng Q, Shen $L$ and Wu G. (2018): Interleukin-6 induces fat loss in cancer cachexia by promoting white adipose tissue lipolysis and browning. Lipids in Health and Disease, 17(1): 14-21.

34. Hao Y, Kuang Z, Jing J, Miao J, Mei LY, Lee RJ, Kim S, Choe S, Krause DC and Lau GW. (2014): Mycoplasma pneumoniae modulates STAT3- STAT6/EGFR-FOXA2 signaling to induce over expression of airway mucins. Infect Immun., 82(12): 5246-5255.

35. Harris JF, Fischer MJ, Hotchkiss JR, Monia BP, Randell SH, Harkema JR and Tesfaigzi Y. (2005): Bcl-2 sustains increased mucous and epithelial cell numbers in metaplastic airway epithelium. Am J Respir Crit Care Med., 171(7): 764-772.

36. Im S-A, Lee Y-R, Lee Y-H, Lee M-K, Park YI, Lee S, Kim K and Lee Ch-K. (2010): In vivo evidence of the immunomodulatory activity of orally administered Aloe vera gel. Arch Pharm Res., 33(3):451- 456.

37. Jensen EC. (2013): Quantitative Analysis of Histological Staining and Fluorescence Using Image J. Anat Rec., 296(3): 378-381.

38. Kafi M, Tamadon A and Saeb M. (2015): The relationship between serum adiponectin and postpartum luteal activity in high producing dairy cows. Theriogenology, 83 (8): 1264-1271.

39. Kim BC, Kim YS, Lee JW, Seo JH, Ji ES, Lee H, Park YI and Kim CJ.(2011): Protective effect of coriolus versicolor cultivated in citrus extract against nitric oxide Induced apoptosis in human neuroblastoma 
SK N MC cells. Exp Neurobiol., 20(2): 100 109.

40. Klaikeaw $\mathbf{N}, \quad$ Wongphoom $\quad \mathbf{J}$, Werawatganon D, Chayanupatkul $M$ and Siriviriyakul P. (2020): Anti-inflammatory and anti-oxidant effects of aloe vera in rats with non-alcoholic steatohepatitis. World Journal of Hepatology, 12(7): 363-377.

41. Kumar R, Singh AK, Gupta A, Bishayee A and Pandey AK. (2019): Therapeutic potential of Aloe vera-A miracle gift of nature. Phytomedicine, 60: 152996. 117-128.

42. Lee JH, Kim YS, Song KS, Ryu HR, Sung JH, Park JD, Park HM, Song NM, Shin BS, Marshak D, Ahn K, Lee JE and Yu IJ. (2013): Biopersistence of silver nanoparticles in tissues from Sprague Dawley rats. Part Fibre Toxicol., 10(36): 1-11.

43. Li WC, Zou ZJ, Zhou MG, Chen L, Zhou L, Zheng YK and He ZJ. (2015): Effects of simvastatin on the expression of inducible NOS in acute lung injury in septic rats. Int $\mathbf{J}$ Clin Exp Pathol., 8(11): 1510615111.

44. Liu X, Jin X, Yu D and Liu G. (2019): Suppression of NLRP3 and NF $\kappa \mathrm{B}$ signaling pathways by $\alpha$ Cyperone via activating SIRT1 contribute to attenuation of LPS induced acute lung injury in mice. Int Immunopharmacol., 76: 105886 .

45. Maan AA, Nazir A, Khan MKI, Ahmad T, Zia R, Murid M and Abrar M. (2018): The therapeutic properties and applications of Aloe vera: A review. Journal of Herbal Medicine, 12: $1-10$.

46. Makama S, Kloet SK, Piella J, van den Berg $H$, de Ruijter NCA, Puntes VF, Rietjens IMC and van den Brink NW (2018): Effects of systematic variation in size and surface coating of silver nanoparticles on their in vitro toxicity to macrophage RAW 264.7 cells. Toxicological Sciences, 162(1): 79-88.

47. Malek-Mohammadi $R$, Roghani $M$ and Salami M. (2015): The effect of aqueous extracts of Melissa officinalis on the oxidative stress indices in the midbrain tissue. FEYZ, 19(1): 8-14.
48. Moradi-Sardareh H, Basir HRG, Hassan ZM, Davoudi M, Amidi F and Paknejad M. (2018): Toxicity of silver nanoparticles on different tissues of $\mathrm{Balb} / \mathrm{C}$ mice. Life Sciences, 211: 81-90.

49. Nna VU, Ofem OE, Oka VO, Aluko EO and Ofutet EO. (2014): Comparative effects of Aloe vera gel and aqueous leaf extract of Viscum album on bilirubin excretion in streptozotocin - induced diabetic rats. Int $\mathbf{J}$ Biochem Res Rev., 4(1): 99-115.

50. Nouno T, Okamoto $M$, Ohnishi $K$, Kaieda S, Tominaga M, Zaizen Y, Ichiki M, Momosaki S, Nakamura M, Fujimoto K, Fukuoka J, Shimizu S, Komohara Y and Hoshino T. (2019): Elevation of pulmonary CD163+ and CD204+ macrophages is associated with the clinical course of idiopathic pulmonary fibrosis patients .J Thorac Dis., 11(9): 4005-4017.

51. Paixão L, Ramos RB, Lavarda A, Morsh DM and Spritzer PM. (2017): Animal models of hyperandrogenism and ovarian morphology changes as features of polycystic ovary syndrome: a systematic review. Reprod Biol Endocrinol.,15(1):12-19.

52. Paulsen CE, Truong TH, Garcia FJ, Homann A, Gupta V, Leonard SE and Carroll KS. (2011): Peroxide-dependent sulfenylation of the EGFR catalytic site enhances kinase activity. Nat Chem Biol., 8(1): 57-64.

53. Radha MH and Laxmipriya NP. (2015): Evaluation of biological properties and clinical effectiveness of Aloe vera: a systematic review. J Tradit Complement Med., 5(1): 21-26.

54. Rahman $S$, Carter $P$ and Bhattarai $N$. (2017): Aloe Vera for Tissue Engineering Applications. Journal of Functional Biomaterials, 8(1): 6-21.

55. Rahoui W, Merzouk H, El Haci IA, Bettioui R, Azzi R and Benali M. (2018): Beneficial effects of Aloe vera gel on lipid profile, lipase activities and oxidant/antioxidant status in obese rats. Journal of Functional Foods, 48: 525-532. 


\section{Mona Mohamed Abd El-Galil and Ahmad Mohammad Farag Alkot}

56. Ramos-Vara JA, Kiupel M, Baszler T, Bliven L, Brodersen B, Chelack B, Czub S, Piero F D, Dial S, Ehrhart E J, Graham T, Manning L, Paulsen D, Valli V E and West K. (2008): American association of veterinary laboratory diagnosticians subcommittee on standardization of immunohistochemistry: suggested guidelines for immunohistochemical techniques in veterinary diagnostic laboratories. J Vet Diagn Invest., 20: 393-413.

57. Sánchez M, González-Burgos E, Iglesias I and Gómez-Serranillos MP. (2020): Pharmacological Update Properties of Aloe Vera and its Major Active Constituents. Molecules, 25(6): 1324-1332.

58. Setyawati MI, Tay CY, Chia SL, Goh SL, Fang W, Neo MJ and Xie JP. (2013): Titanium dioxide nanomaterials cause endothelial cell leakiness by disrupting the homophilic interaction of VE-cadherin. Nature Communications, 4:1673: 1-12.

59. Shi J, Sun X, Lin Y, Zou X, Li Z, Liao Y, Du $M$ and Zhang H. (2014): Endothelial cell injury and dysfunction induced by silver nanoparticles through oxidative stress via IKK/NF- $\kappa$ B pathways. Biomaterials, 35(24): 6657-6666.

60. Singh B, Mohan R, Maurya A and Mishra G. (2018): Phytoconstituents and biological consequences of: A focused review Aloe vera. Asian Journal of Pharmacy and Pharmacology, 4(1): 17-22.

61. Sumi FA, Sikder B, Rahman MM, Lubna SR, Ulla A, Hossain MH, Jahan IA, Alam MA and Subhan N. (2019): Phenolic Content Analysis of Aloe vera Gel and Evaluation of the Effect of Aloe Gel Supplementation on Oxidative Stress and Fibrosis in IsoprenalineAdministered Cardiac Damage in Rats. Preventive Nutrition and Food Science, 24(3): 254-264.

62. Syafiuddin A, Salim MR, Kueh ABH, Hadibarata T and Nur H. (2017): A review of silver nanoparticles: research trends, global consumption, synthesis, properties, and future challenges. Journal of the Chinese Chemical Society, 64(7): 732-756.
63. Tabatabaei SRF, Ghaderi S, BahramiTapehebur M, Farbood Y and Rashno $M$. (2017): Aloe vera gel improves behavioral deficits and oxidative status in streptozotocininduced diabetic rats. Biomedicine \& Pharmacotherapy, 96: 279-290.

64. Tatler AL, Habgood A, Porte J, John AE, Stavrou A, Hodge E, Kerama-Likoko C, Violette SM, Weinreb PH, Knox AJ, Laurent G, Parfrey H, Wolters PJ, Wallace W, Alberti S, Nordheim A and Jenkins G. (2016): Reduced Ets Domain-containing Protein Elk1 Promotes Pulmonary Fibrosis via Increased Integrin $\alpha v \beta 6$ Expression. J Biol Chem., 291(18): 9540-9553.

65. Tavares P, Balbinot F, de Olivera HM, Fagundes GE, Venẩncio $\mathrm{M}$, Ronconi JVV, Merlini A, Streck EIL, Paula MM and de Andrade VM. (2012): Evaluation of genotoxic effect of silver nanoparticles (AgNPs) in vitro and in vivo. J Nanopart Res., 14(791): 1-8.

66. Tortella GR, Rubilar O, Durán N, Diez MC, Martínez M, Parada J and Seabra AB. (2020): Silver nanoparticles: Toxicity in model organisms as an overview of its hazard for human health and the environment. Journal of Hazardous Materials, 390: 121974. 263282.

67. Valerio-García RC, Carbajal-Hernández AL, Martínez-Ruíz EB, Jarquín-Díaz VH, Haro-Pérez $C$ and Martínez-Jerónimo $F$. (2017): Exposure to silver nanoparticles produces oxidative stress and affects macromolecular and metabolic biomarkers in the goodeid fish Chapalichthys pardalis. Science of the Total Environment, 583(12): 308-318.

68. Wu T and Tang M. (2018): Review of the effects of manufactured nanoparticles on mammalian target organs. Journal of Applied Toxicology, 38(1): 25-40.

69. Yang R-Q, Guo P-F, Ma Z, Chang C, Meng Q-N, Gao Y, Khan I, Wang X-B and Cui ZJ. (2020): Effects of simvastatin on iNOS and caspase 3 levels and oxidative stress following smoke inhalation injury. Molecular Medicine Reports, 22 (4): 3405-3417. 
70. Yin N, Yao X, Zhou Q, Faiola $F$ and Jiang G. (2015): Vitamin $\mathrm{E}$ attenuates silver nanoparticle-induced effects on body weight and neurotoxicity in rats. Biochemical and Biophysical Research Communications, 458(2): 405-410.

71. Yousef MI, Abuzreda AA and Kamel MAN. (2019): Cardiotoxicity and lung toxicity in male rats induced by long term exposure to iron oxide and silver nanoparticles. Experimental and Therapeutic Medicine, 18(6): 4329-4339.
72. Zhang L, Wu L, Si Y and Shu K. (2018): Size-dependent cytotoxicity of silver nanoparticles to Azotobacter vinelandii: Growth inhibition, cell injury, oxidative stress and internalization. PLoS One, 13(12): e0209020.

73. Zhu X, Cao W, Chang B, Zhang L, Qiao P, Li X, Si L, Niu Y and Song Y. (2016): Polyacrylate / nanosilica causes pleural and pericardial effusion, and pulmonary fibrosis and granuloma in rats similar to those observed in exposed workers. International Journal of Nanomedicine, 11: 1593-1605. 


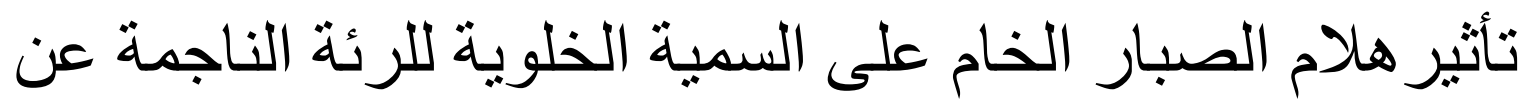
الجسيمات النانوية الفضية في ذكور الجرذان الفي البية البيضاء البالغة:

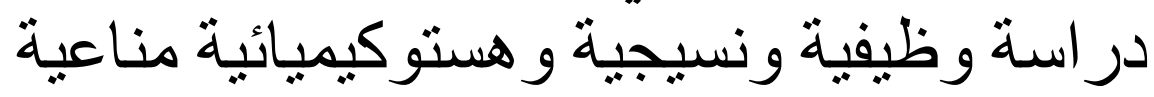
منى محمد عبد الجليل*، أحمد محمد فرج القط** ولهن *قسم الهستولوجيا وبيولوجيا الخلية، كلية الطب (بنات)، جامعة الأزهر ":قسم الفيسيولوجيا الطبية، كلية الطب (بنين)، جامعة الأزهر

E-mail: medicalmona2009@yahoo.com

Institutional e-mail address: mona.elsayed@azhar.edu.eg

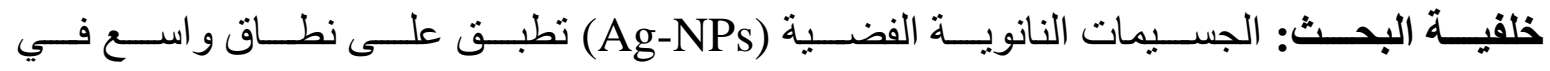

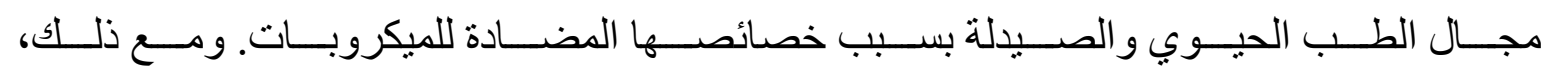

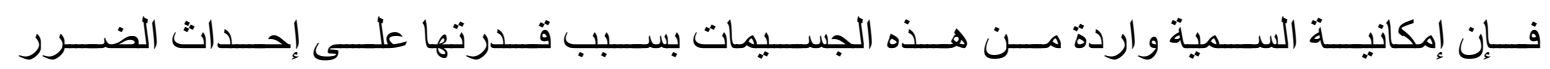

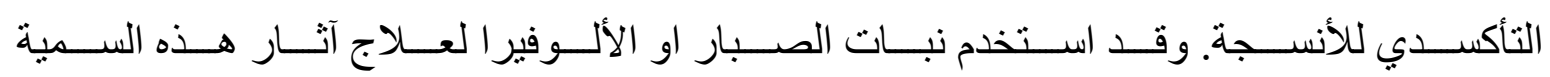
لما له من خصائص مضادة للأكسدة و الالتهابات.

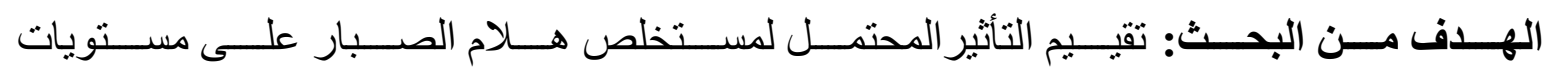

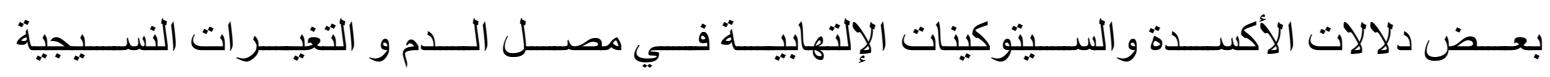

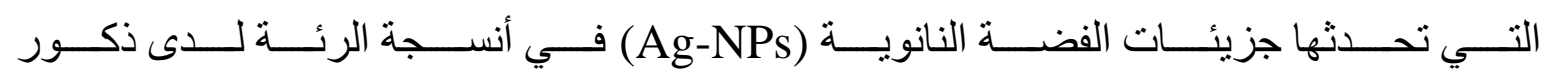
الجرذان البيضاء البالغة.

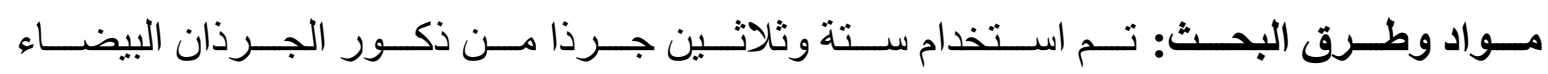
البالغة قسمت الى خمس مجمو عات: • المجموعة الأولى: المجمو عة الضابطة.

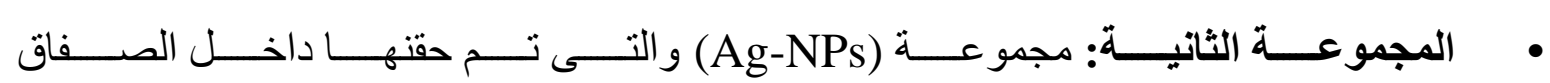

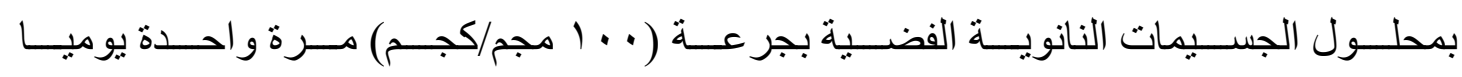
لمدة ؛ اسابيع متتالية. 


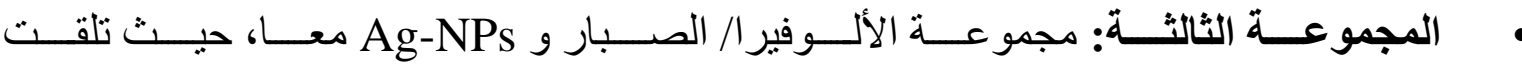

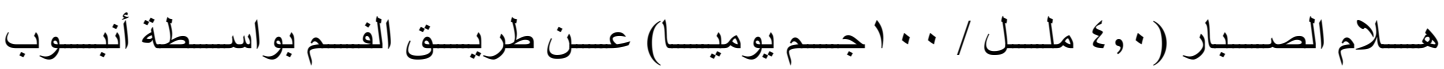

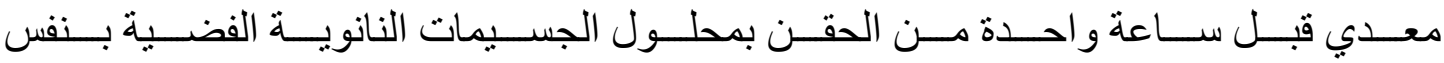
الجر عة و المدة مثل المجمو عة الثانية.

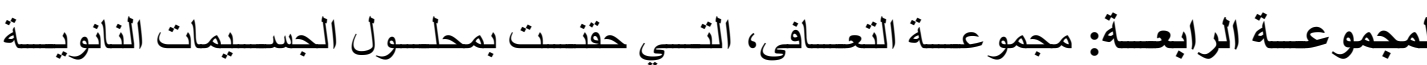
الفضية (Ag-NPs) ثم تركت دون تدخل علاجي لمدة ؛ أسابيع متتالية.

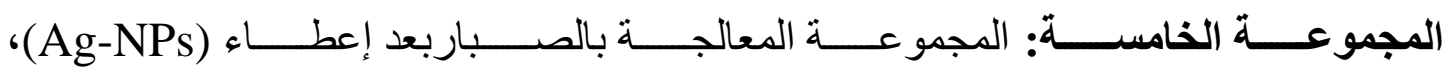

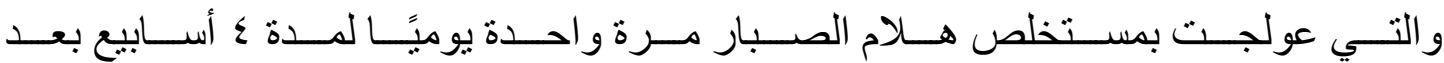
Ag-NPs (إستحداث الضرر بمحلول

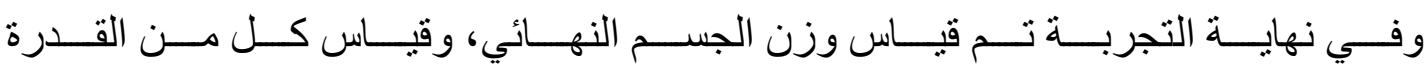

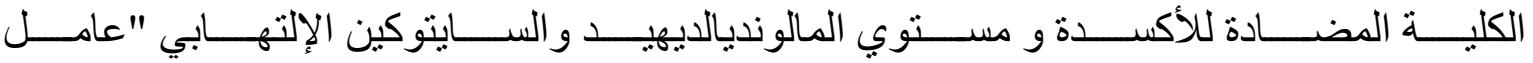

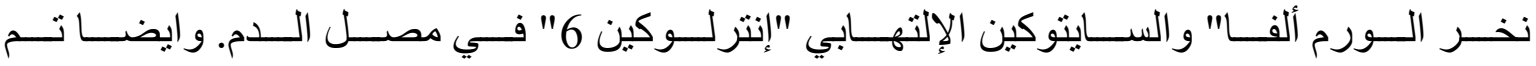

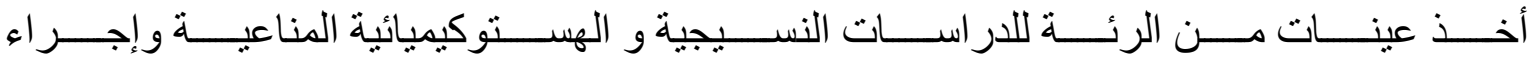
التحليلات النسيجية و الإحصائية لها.

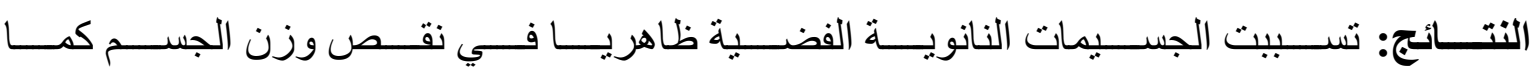

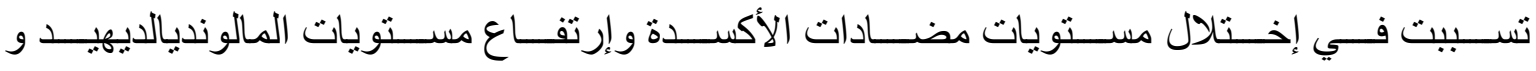

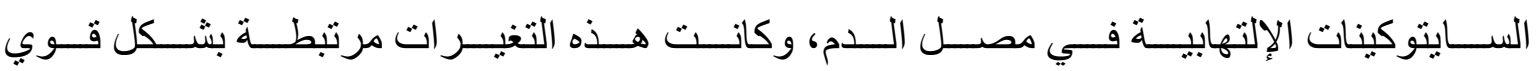

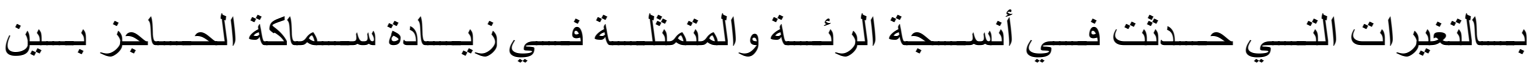

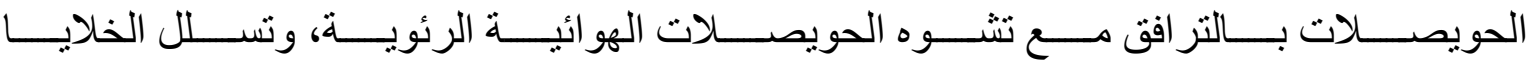

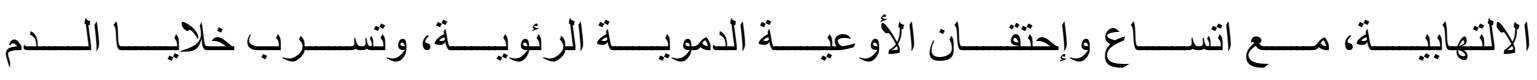

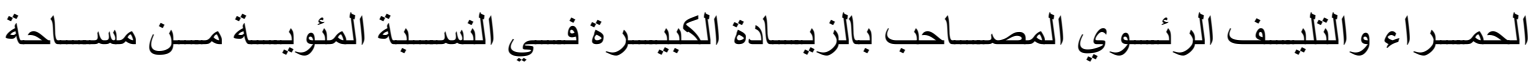

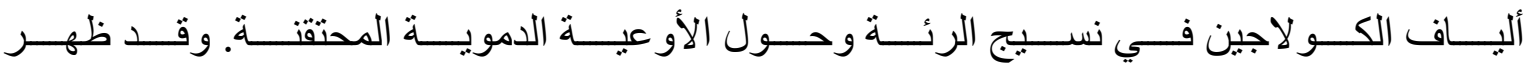

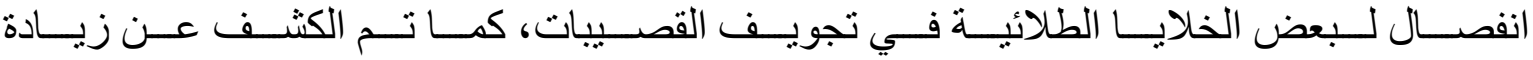

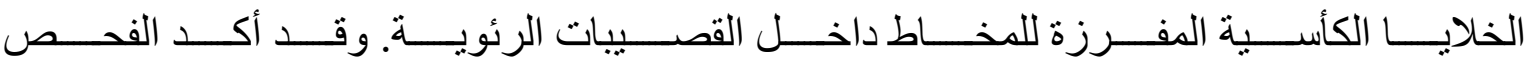

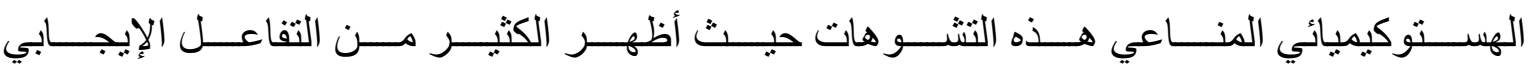

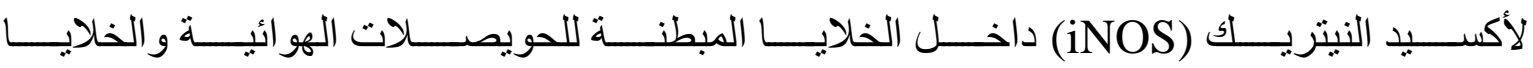

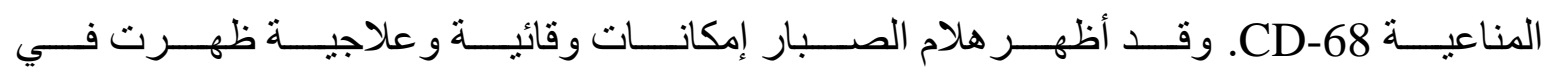


604

Mona Mohamed Abd El-Galil and Ahmad Mohammad Farag Alkot

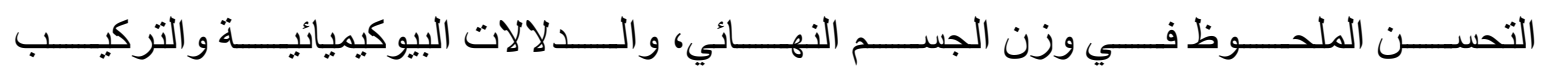
النسيجي، مع تفوق التأثير الوقائي على التأثير العلاجي.

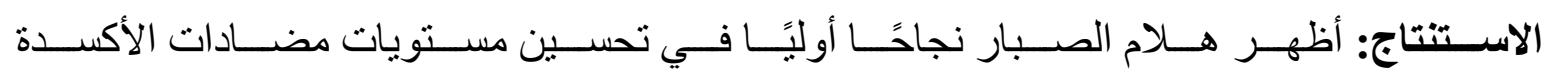

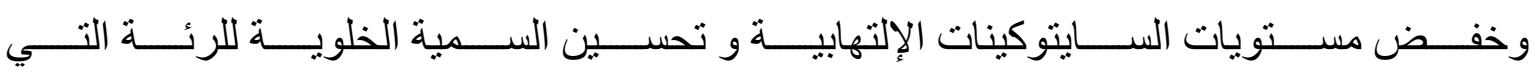

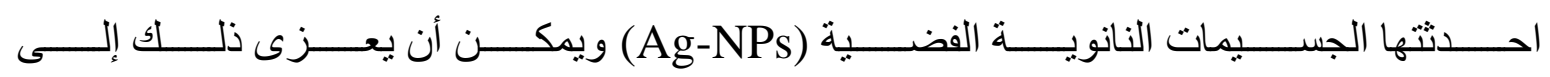
خصائصه الكيميائية النباتية المضادة للأكسدة والالتهابات. الكلمات الدالة: الجسيمات النانوية الفضية، الصبار، الرئة، مضادات الأكسدة. 